\title{
Combined Space and Water Heating: Next Steps to Improved Performance
}

B. Schoenbauer, D. Bohac, and P. Huelman NorthernSTAR 


\section{NOTICE}

This report was prepared as an account of work sponsored by an agency of the United States government. Neither the United States government nor any agency thereof, nor any of their employees, subcontractors, or affiliated partners makes any warranty, express or implied, or assumes any legal liability or responsibility for the accuracy, completeness, or usefulness of any information, apparatus, product, or process disclosed, or represents that its use would not infringe privately owned rights. Reference herein to any specific commercial product, process, or service by trade name, trademark, manufacturer, or otherwise does not necessarily constitute or imply its endorsement, recommendation, or favoring by the United States government or any agency thereof. The views and opinions of authors expressed herein do not necessarily state or reflect those of the United States government or any agency thereof.

Available electronically at SciTech Connect http:/www.osti.gov/scitech

Available for a processing fee to U.S. Department of Energy

and its contractors, in paper, from:

U.S. Department of Energy

Office of Scientific and Technical Information

P.O. Box 62

Oak Ridge, TN 37831-0062

OSTI http://www.osti.gov

Phone: 865.576 .8401

Fax: 865.576.5728

Email: reports@osti.gov

Available for sale to the public, in paper, from:

U.S. Department of Commerce

National Technical Information Service

5301 Shawnee Road

Alexandria, VA 22312

NTIS http://www.ntis.gov

Phone: 800.553 .6847 or 703.605 .6000

Fax: 703.605.6900

Email: orders@ntis.gov 


\title{
Combined Space and Water Heating: Next Steps to Improved Performance
}

\author{
Prepared for: \\ The National Renewable Energy Laboratory \\ On behalf of the U.S. Department of Energy's Building America Program \\ Office of Energy Efficiency and Renewable Energy \\ 15013 Denver West Parkway \\ Golden, CO 80401 \\ NREL Contract No. DE-AC36-08GO28308 \\ Prepared by: \\ B. Schoenbauer, D. Bohac, and P. Huelman \\ NorthernSTAR Building America Partnership \\ 2004 Folwell Avenue \\ Minneapolis, MN 55108 \\ NREL Technical Monitor: Stacy Rothgeb \\ Prepared under Subcontract No. KNDJ-0-40338-04
}

July 2016 
The work presented in this report does not represent performance of any product relative to regulated minimum efficiency requirements.

The laboratory and/or field sites used for this work are not certified rating test facilities. The conditions and methods under which products were characterized for this work differ from standard rating conditions, as described.

Because the methods and conditions differ, the reported results are not comparable to rated product performance and should only be used to estimate performance under the measured conditions. 


\section{Contents}

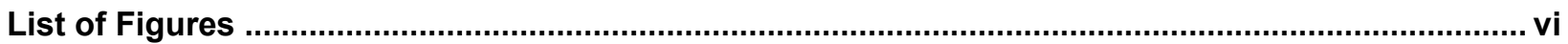

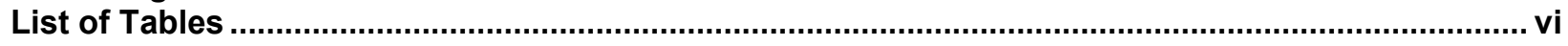

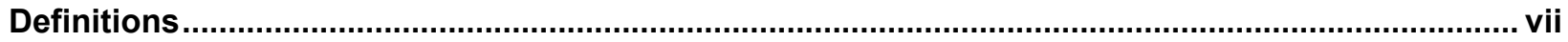

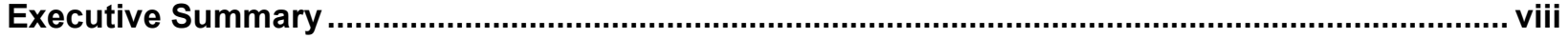

1 Problem Statement

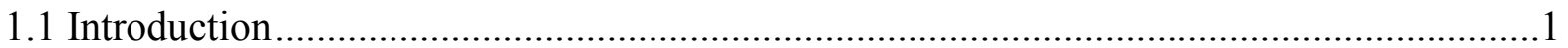

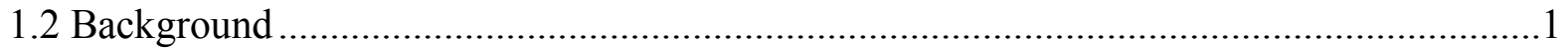

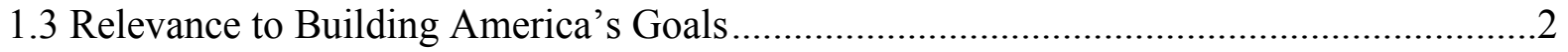

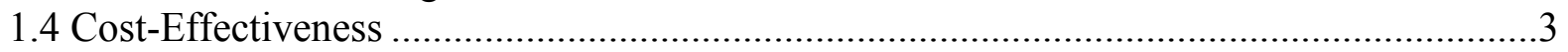

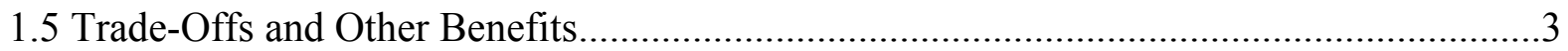

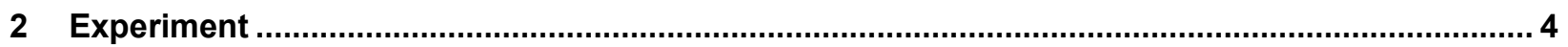

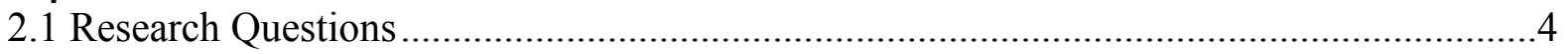

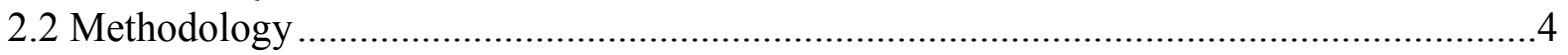

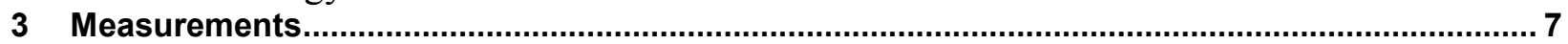

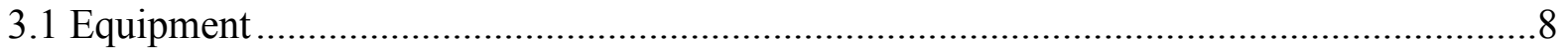

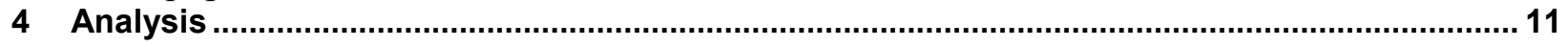

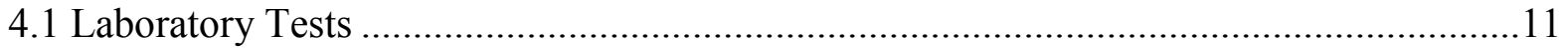

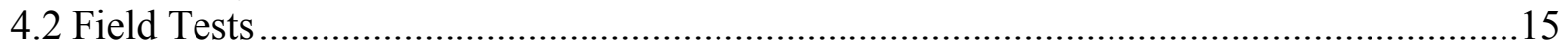

4.2.1 Set Point Reduction.................................................................................. 15

4.2.2 Domestic Hot Water Priority ........................................................................... 16

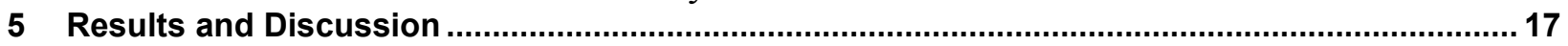

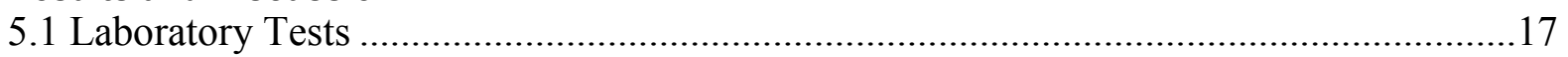

5.1.1 Tankless Water Heaters ............................................................................ 21

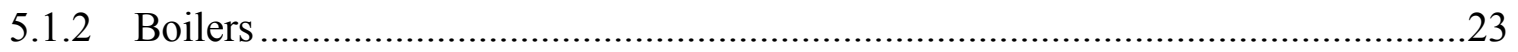

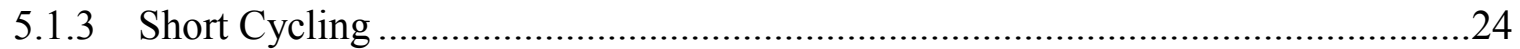

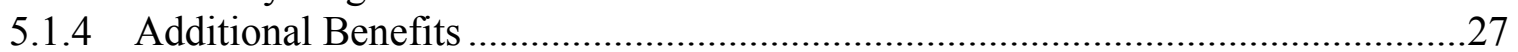

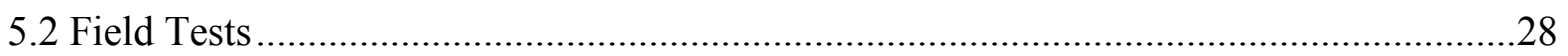

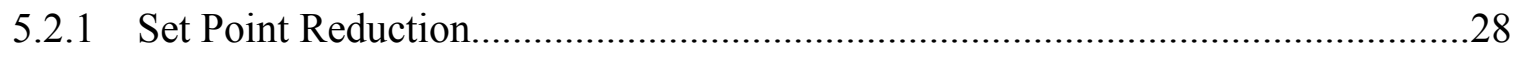

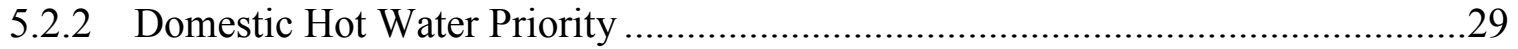

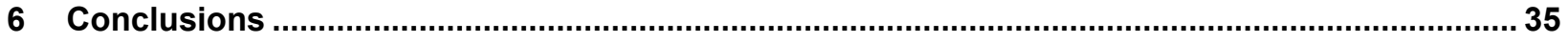

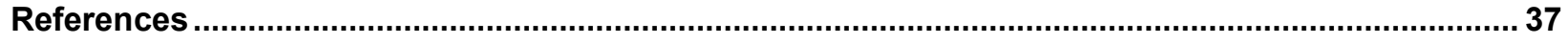

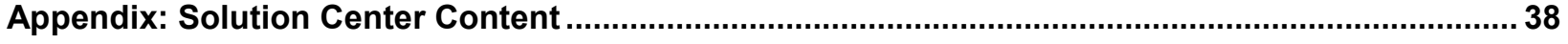




\section{List of Figures}

Figure 1. Photos of test laboratory with combi system installations ............................................. 9

Figure 2. Combi system space-heating operating capacity: Eternal hybrid water heater ................ 13

Figure 3. Daily outside air temperature to space-heating load relationships for three homes ........ 14

Figure 4. Seasonal DHW use profiles ....................................................................................... 15

Figure 5. Daily space-heating load by outdoor air temperature for a field site ................................. 16

Figure 6. Steady-state space-heating efficiency for the Vertex SWH .............................................. 17

Figure 7. Combined (space and DHW) efficiencies for both control strategies .............................. 19

Figure 8. Space-heating efficiency versus return water temperature for the Rinnai TWH................ 22

Figure 9. TWH space-heating input versus output relationship ........................................................ 22

Figure 10. Water heater and boiler-based combi system plumbing configurations ........................ 23

Figure 11. Steady-state space-heating test results: Navien boiler ................................................. 24

Figure 12. Cycling operation of an SWH-based fixed input combi system using a Polaris water

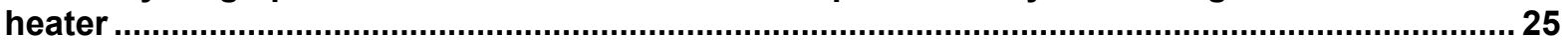

Figure 13. Cycling performance for combi systems with modulating burners (Phoenix water

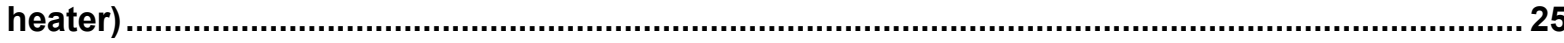

Figure 14. Impacts of short space-heating events on combi efficiency .......................................... 26

Figure 15. Conditioned space temperature during peak heating season for days with high and

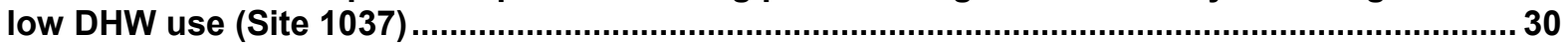

Figure 16. Simultaneous DHW and space-heating draws with a TWH-based combi system ........... 31

Figure 17. A small DHW draw interrupted by a space-heating draw with a TWH-based combi system

Figure 18. Simultaneous DHW and space heating draws on a SWH-based combi system .............. 33

Figure 19. DHW priority operation on a combi boiler system ....................................................... 34

Unless otherwise noted, all figures were created by NorthernSTAR.

\section{List of Tables}

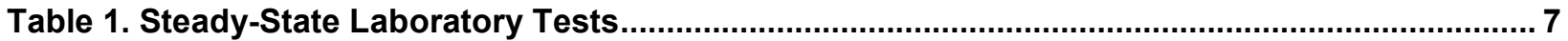

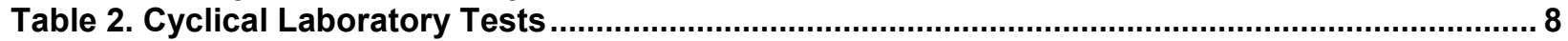

Table 3. Laboratory Instrumentation Equipment ................................................................................ 9

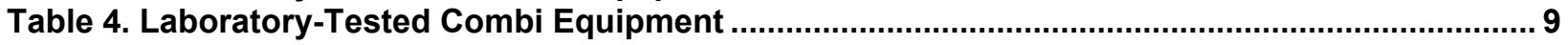

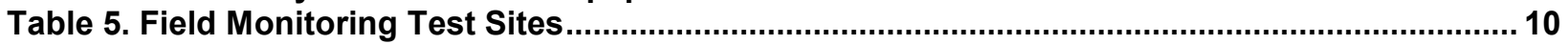

Table 6. Eternal Water Heater-Based Combi System Performance Bins for Operation at 5 GPM

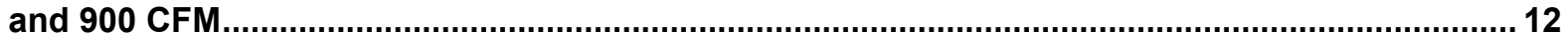

Table 7. Space-Heating Characteristics for Binned Analysis............................................................. 13

Table 8. Steady-State Space Heating Laboratory Results for the Vertex SWH ............................. 18

Table 9. Energy Use and Savings from Control Strategies .............................................................. 20

Table 10. Impacts of Short Space-Heating Events on Combi Efficiency ........................................ 26

Table 11. Eternal Water Heater Based Combi System Performance Bins for Operation at 5 GPM

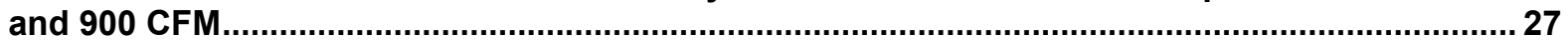

Table 12. Field Monitoring Sites and Combi System Equipment..................................................... 28

Table 13. Efficiency and Energy Use Improvements from Set Point Reduction ............................ 29

Table 14. Steady-State Space Heating Laboratory Results for SWHs (2.5 GPM and 900 CFM)....... 29

Unless otherwise noted, all tables were created by NorthernSTAR. 


\section{Definitions}

AFUE

AHU

BEoptтм

CFM

DHW

GPD

GPM

ND

SWH

TWH
Annual fuel utilization efficiency

Air handling unit

Building Energy Optimization software

Cubic feet per minute

Domestic hot water

Gallons per day

Gallons per minute

Natural draft

Storage water heater

Tankless water heater 


\section{Executive Summary}

A combined space- and water-heating (combi) system uses a high-efficiency direct-vent burner that eliminates safety issues associated with natural draft appliances. Past research with these systems shows that using condensing water heaters or boilers with hydronic air handling units can provide both space and water heating with efficiencies of $90 \%$ or higher. ${ }^{1}$ Improved controls have the potential to reduce complexity and improve upon the measured performance.

This project demonstrates that controls can significantly benefit these first-generation systems. Laboratory tests and daily load/performance models showed that the set point temperature reset control produced a $2.1 \%-4.3 \%(20-40$ therms/year) savings for storage and hybrid water heater combi systems operated in moderate-load homes. The full modulation control showed additional savings over set point control (in high-load homes almost doubling the savings: $4 \%-5 \%$ over the no-control case). At the time of installation the reset control can be implemented for $\$ 200-\$ 400$, which would provide paybacks of 6-25 years for low-load houses and 3-15 years for high-load houses. Full modulation implementation costs would be similar to the outdoor reset and would provide paybacks of 5-1/2-20 years for low-load houses and $2-1 / 2-10$ years for high-load houses.

Field monitoring of five homes was conducted to measure the energy savings impact of set point reduction only. The field testing and analysis showed that a reduction in set point temperature from $140^{\circ}-130^{\circ} \mathrm{F}$ resulted in an average reduction in return water temperature of $4^{\circ} \mathrm{F}$. These homes experienced savings of $1 \%-4 \%$ (an average of $2.5 \%$ ) on their annual energy bills with the reduced set point.

Although the control strategies provided energy cost savings, the greatest benefit may be a simpler commissioning process that more reliably results in high-efficiency operation. For instance, previous research by the U.S. Department of Energy's Building America research team NorthernSTAR has shown that improper commissioning or inaccurate characterization of the design heating load can reduce combi system efficiency from approximately $90 \%$ to $75 \%$. These control strategies would allow the system to automatically reduce capacity to the most efficient operating point and still meet the load. For example, the study showed that design loads were typically overestimated and had additional safety factors applied. This approach resulted in optimized design loads that were much higher than the actual design loads; therefore, the return water temperature increased and the efficiency decreased. If the same systems were installed with a set point reset or fully modulating control, the system would operate at a lower-capacity stage; water temperature would decrease and efficiency would increase. The control system would thus reduce the number of design calculations and the amount of time that would be required to properly install and commission a combi system.

\footnotetext{
${ }^{1}$ Similar to the results reported for this research, efficiencies reported for combi systems in these previous research studies are not comparable to regulated product ratings and should be used only to estimate performance under the measured conditions.
} 


\section{Problem Statement}

\subsection{Introduction}

Better insulation and tighter envelopes reduce space-heating loads for new and existing homes. In many cases a single heating plant can provide space heating and domestic hot water (DHW). The systems studied are called combination (combi) systems and use high-efficiency direct-vent burners that eliminate the safety issues associated with natural draft (ND) appliances.

Single heating plants that supply both forced-air space heating and water heating have been in use for many years. Bohac et al. (1991) installed and monitored combis in small commercial and multifamily buildings in 1989. These systems used ND storage water heaters (SWHs) as the heating plants. The $1-1 / 2$ years of monitored operation demonstrated that these systems could be reliably installed, perform without failure, and save energy. The combi systems in this project had annual fuel utilization efficiency (AFUE) ratings of at least $78 \%$ and replaced ND water heaters with efficiencies of about $50 \%$ and furnaces with AFUEs around $60 \%$. The study found an average energy savings of $24 \%$.

The U.S. Department of Energy's Building America research team NorthernSTAR has used combi systems to replace natural gas forced-air distribution system furnaces and tank type water heaters. The combi systems consisted of a water heater or boiler heating plant teamed with a hydronic air handling unit (AHU) that included an AHU, a water coil, and a water pump to circulate water between the heating plant and the coil. The combi water heater or boiler had a separate circuit for DHW. Various options for DHW priority, DHW tempering, and heating plant temperature set point control were considered.

Previous projects characterized the installed performance of combi systems that used several types of condensing heating plants (Schoenbauer et al. 2014). Although the primary objective was to measure installed performance of combi systems, analyses were conducted before and after installation to estimate energy savings. Combi systems reduced natural gas consumption for space and water heating by $19 \%$. This project also monitored the operational parameters and delivery capacities of the system. These measurements allowed for the identification of several potential control improvements. A discussion and evaluation of those opportunities are presented here.

\subsection{Background}

Historically, mechanical contractors have custom engineered and pieced together combi systems in the field. They focused on assembling functional systems and often paid little attention to efficiency and optimization. As high-efficiency condensing water heaters and boilers gain a larger share of the residential market, there is greater potential to use these systems to improve the efficiency of providing space heating and DHW.

Twenty years ago a combi system that used a noncondensing water heater could provide energy savings when it replaced an older low-efficiency furnace and water heater. Currently, in many parts of the country furnaces with $90 \%+$ AFUE ratings are standard. Thomas et al. (2011) used laboratory testing to demonstrate that when combi systems replace mechanical equipment in modern homes those systems must use condensing heating plants to achieve similar or improved energy performance. 
Schoenbauer et al. (2014) conducted a 200-home implementation project and a 20-home detailed monitoring project. This project collected valuable information about combi system performance and occupant comfort. These authors showed that properly configured combi systems typically operate at an annual efficiency of $85 \%-92 \%$ and result in $19 \%$ average savings over ND water heaters and noncondensing furnaces. Careful monitoring also highlighted potential areas for improvement that were analyzed by this project.

\subsection{Relevance to Building America's Goals}

Combi systems have the potential to significantly reduce home energy use. A properly installed combi system can provide approximately $20 \%$ natural gas savings compared to an $80 \%$ AFUE furnace and a $60 \%{ }^{2}$ energy factor water heater. Replacing an ND water heater with a direct-vent heating plant also allows the home to be more airtight without causing combustion safety issues. Such replacement also eliminates air infiltration through the combustion makeup air duct. These two features can further improve the energy performance of a home.

Combi systems are feasible for typical houses in most climate regions. In colder climates the application may not be possible in very large homes with poorly insulated and leaky envelopes. Some currently available equipment can meet space-heating design loads up to $70,000 \mathrm{Btu} / \mathrm{h}$ while still operating in the condensing mode. Higher-capacity hydronic coils than those that are traditionally available would allow current heating plans to meet even higher space-heating loads.

Combi systems can provide high-efficiency space and water heating at a lower cost than two high-efficiency appliances (furnace and water heater). Previously, each installation required customized contractor designs, equipment selection, and commissioning to ensure the proper installation, sizing, and operation to achieve efficient performance. The installation and optimization process used by NorthernSTAR for the previous field project was summarized in the final report. Future work will develop this experience into a full measure guideline for design, installation, optimization, and verification of combi system performance.

In addition to improving the efficiency and energy savings of combi systems, this project addresses the installation and design difficulties with combi systems. Improved control can reduce the necessity of having a system designed and manually adjusted to narrowly defined and optimized parameters. Combi system efficiency is largely a factor of the water temperature returning to the heating plant from the AHU and burner cycling characteristics. Lower return temperatures and longer cycles produce higher system efficiency. All current AHUs have a constant airflow rate and a constant water circulation flow rate for the heating mode. To achieve the best performance, these flow rates must be adjusted to meet the house design heating load and minimize the return water temperature. Variable air and water flow rate control would allow a single AHU to provide more efficient performance over a wider range of heating loads and should eliminate time-consuming manual adjustments to the water flow rate. The controls improve efficiency by allowing the system to operate at a lower average return water temperature and longer cycles.

\footnotetext{
${ }^{2}$ For a gas-fired water heater with a rated storage volume of 40 gal.
} 


\subsection{Cost-Effectiveness}

Installing a high-efficiency combi system may cost less than installing a similarly efficient separate furnace and water heater. In a retrofit application in Minnesota, a homeowner can expect to pay approximately $\$ 4,250$ for a high-efficiency $(90 \%-98 \%$ AFUE) furnace and $\$ 5,300$ for a high-efficiency (0.80-0.95 energy factor) SWH. As the number of high-efficiency water heater installations increased over the past few years, the installed cost dropped dramatically. In the Minneapolis area, contractors with limited combi-systems experience currently bid a highefficiency system for $\$ 8,200$ - on average with a typical range of $\$ 6,500-\$ 10,000$.

\subsection{Trade-Offs and Other Benefits}

Combi systems have several secondary benefits. The system replaces a separate furnace and water heater with a single boiler or water heater. This reduces the number of gas lines and exhaust vents from two to one and often reduces the equipment footprint. A single highefficiency burner also has combustion safety and venting benefits. The high-efficiency combi heating plants have power-vent or sealed combustion burners that eliminate combustion spillage concerns for tight houses. 


\section{Experiment}

\subsection{Research Questions}

The test laboratory and field research addressed the following research questions:

- What is the effect of improved control methods on combi system energy efficiency?

- What are the cost and comfort impacts of several improved control strategies?

- Can improved control strategies limit the amount of site-specific design and commissioning necessary for high-performance combi systems?

- Do combi systems have capacity issues that can be solved through improved controls?

\subsection{Methodology}

This project builds on past research that shows combi systems that use condensing water heaters or boilers with hydronic AHUs can provide space and water heating with efficiencies of $90 \%$ or higher. Condensing combi systems are still relatively new and complex; they often require onsite engineering and optimization to achieve desired performance. Improved controls have the potential to reduce some of this installation and operational complexity and improve upon the measured performance. The control measures evaluated in the laboratory include temperature set point control (outdoor reset and/or turndown after heating season), space-heating modulation (both water flow and airflow) and DHW priority. The benefits to installation, sizing, and optimization were characterized for all three control schemes. Set point control and spaceheating modulation were analyzed for efficiency and energy-saving improvements through laboratory and field testing.

Set point reset. The supply water set point temperature reset by outdoor air temperature control method has been widely used for commercial and residential boilers. This control method has several potential benefits for combi systems as well:

- Reducing the set point temperature in the winter and shoulder seasons increases the system's thermal efficiency. Laboratory tests at a range of water temperature set points were used to characterize the space-heating efficiency and output impacts.

- Lower set points reduce the standby losses of combi systems with internal water storage capacity.

- The reset control increases system runtimes. As the reset control reduces the set point temperature the system output is also reduced; this mirrors the reduction in space-heating load as outdoor temperatures rise. Set point temperature reductions should not reduce the system output capacity below the space-heating load of the home.

Flow rate modulation. Airflow and water flow rate modulation can also improve the performance and efficiency of combi systems. With current equipment airflow and water flow can only be varied manually and typically remain fixed throughout the product's lifetime. Full modulation or multiple step modulation allows the combi system to operate at an optimized output rate that depends on demand. This approach has several potential benefits: 
- Lower output rates increase runtimes, which reduces the impacts of short cycling and improves comfort.

- Laboratory testing indicates that lower output rates (achieved by reducing temperature, water flow rate, or airflow rate) may yield lower return water temperatures, thus improving efficiency.

- Multiple operating capacities can enable downsizing equipment or using the same equipment in higher load homes. Large air coils are required to achieve high efficiency at peak loads. However, if a combi system with a smaller coil capacity and flow modulation is optimized for less than peak load, the water circulation and airflow rates can be ramped up only when necessary to meet the peak loads. The system efficiency will be lower during peak periods, but it will be higher for the more moderate loads that occur for the greater portion of the heating season.

- This process can also reduce some of the site-specific optimization and engineering. Modulation control allows the combi system to change the output based on the home's need, so the contractor does not need to optimize the system during installation.

Cyclical and steady-state laboratory test results were used to evaluate and optimize these control methods. Cyclical tests quantify the impact of short cycling and determine the cycle length necessary to avoid the efficiency impacts. Steady-state testing at various water flows and airflows was used to map performance over a range of operating conditions.

Both space-heating control strategies were designed to match the daily space-heating load on the system. For the analysis, the outdoor air temperature was used to determine the daily spaceheating load, which was used to assign each day to the highest-efficiency operating stage with an output capacity higher than the daily load plus a safety factor. This strategy can be implemented in several ways. For the set point reset, the design load can be used to set the combi set point water temperature with respect to the outdoor air temperature, similar to the strategy used for condensing boiler applications. Space-heating runtime can also be used to increase the set point temperature. If the space-heating system runs longer than a specified time (20 minutes, for example) without meeting the thermostat setting, the set point temperature will increase. These control implementation methods can be used for the flow modulation control as well, using algorithms developed based on the operation of a specific system.

DHW priority. The third control strategy considered was DHW priority. This control prevents any space heating when DHW is active. Field data from Schoenbauer et al. (2013) were used to analyze this control method. The potential benefits were assessed in three key areas.

1. What is the impact on the conditioned temperature from locking out space heating? NorthernSTAR's previous study had five sites with boiler systems that had DHW priority installed. Data from these homes were analyzed to determine the temperature variance from DHW priority. Data from all homes were used to determine the frequency of long consistent DHW use that would likely impact the temperature in the conditioned space.

2. Can DHW priority improve DHW supply water temperature consistency during simultaneous events? Water temperatures in homes with and without DHW priority were compared when calls for space heat were initiated during active DHW draws. 
3. DHW priority allows for systems to be sized for independent space and DHW loads instead of the sum of the two loads. Combi systems sized to meet the combined space and DHW loads typically operate at capacities much lower than the combined design capacity. Sizing systems for the two loads separately results in smaller capacity systems, which decreases cycling frequency and allows for better optimization. 


\section{Measurements}

The laboratory testing part of the project characterized the performance of currently available components and developed recommendations for optimized combi system controls. A series of tests on the fully assembled systems was used to evaluate the control methods discussed previously.

- Steady state at a range of parameters (Table 1):

○ Space heating flow rate: 1-5 gallons per minute (GPM)

○ Airflow rate: $500-1000$ cubic feet per minute (CFM)

$\circ$ Heating plant set point temperature $120^{\circ}-140^{\circ} \mathrm{F}$

- Cyclical performance at typical operating parameters (Table 2):

○ Various part-load conditions

- AFUE and Canadian Standard P.9 on/off cycle lengths

- On/off cycles lengths determined from field data from previous studies.

Table 1. Steady-State Laboratory Tests

\begin{tabular}{|c|c|c|c|c|c}
\hline & $\begin{array}{c}\text { Flow Rate } \\
\text { (GPM) }\end{array}$ & $\begin{array}{c}\text { Airflow } \\
(\mathbf{C F M})\end{array}$ & Tset & $\begin{array}{c}\text { Return Air } \\
\text { Temperature } \\
\left({ }^{\circ} \mathbf{F}\right)\end{array}$ & $\begin{array}{c}\text { Ambient } \\
\text { Temperature } \\
\left.\mathbf{(}{ }^{\circ} \mathbf{F}\right)\end{array}$ \\
\hline Test 1 & 2.5 & 900 & 140 & 68 & 70 \\
\hline Test 2 & 2.5 & 900 & 135 & 68 & 70 \\
\hline Test 3 & 2.5 & 900 & 130 & 68 & 70 \\
\hline Test 4 & 2.5 & 900 & 125 & 68 & 70 \\
\hline Test 5 & 2.5 & 900 & 120 & 68 & 70 \\
\hline Test 6 & 5 & 900 & 130 & 68 & 70 \\
Test 7 & 4 & 900 & 130 & 68 & 70 \\
Test 8 & 3 & 900 & 130 & 68 & 70 \\
\hline Test 9 & 2 & 900 & 130 & 68 & 70 \\
Test 10 & 1 & 900 & 130 & 68 & 70 \\
\hline Test 11 & 2.5 & 800 & 130 & 68 & 70 \\
\hline Test 12 & 2.5 & 700 & 130 & 68 & 70 \\
\hline Test 13 & 2.5 & 600 & 130 & 68 & 70 \\
\hline Test 14 & 2.5 & 500 & 130 & 68 & 70 \\
Extra 1 & 0.5 & 500 & 120 & 68 & 70 \\
\hline Extra 2 & 1 & 500 & 120 & 68 & 70 \\
\hline Extra 3 & 2 & 500 & 120 & 68 & 70 \\
\hline
\end{tabular}


Table 2. Cyclical Laboratory Tests

\begin{tabular}{c|c|c|c|c|c|c}
\hline \multirow{2}{*}{} & \multicolumn{5}{|c}{ Cycle Pattern } \\
\cline { 2 - 7 } & Test 1 & Test 2 & Test 3 & Test 4 & Test 5 & Test 6 \\
\hline ON & $1 \mathrm{~min}$ & $5 \mathrm{~min}$ & $10 \mathrm{~min}$ & $10 \mathrm{~min}$ & $30 \mathrm{~min}$ & $45 \mathrm{~min}$ \\
\hline OFF & $10 \mathrm{~min}$ & $10 \mathrm{~min}$ & $10 \mathrm{~min}$ & $50 \mathrm{~min}$ & $30 \mathrm{~min}$ & $15 \mathrm{~min}$ \\
\hline ON & $1 \mathrm{~min}$ & $5 \mathrm{~min}$ & $10 \mathrm{~min}$ & $10 \mathrm{~min}$ & $30 \mathrm{~min}$ & $45 \mathrm{~min}$ \\
\hline OFF & $10 \mathrm{~min}$ & $10 \mathrm{~min}$ & $10 \mathrm{~min}$ & $50 \mathrm{~min}$ & $30 \mathrm{~min}$ & $15 \mathrm{~min}$ \\
\hline ON & $1 \mathrm{~min}$ & $5 \mathrm{~min}$ & $10 \mathrm{~min}$ & $10 \mathrm{~min}$ & $30 \mathrm{~min}$ & $45 \mathrm{~min}$ \\
\hline OFF & $10 \mathrm{~min}$ & $10 \mathrm{~min}$ & $10 \mathrm{~min}$ & $50 \mathrm{~min}$ & $30 \mathrm{~min}$ & $15 \mathrm{~min}$ \\
\hline ON & $1 \mathrm{~min}$ & $5 \mathrm{~min}$ & $10 \mathrm{~min}$ & & & \\
\hline OFF & $10 \mathrm{~min}$ & $10 \mathrm{~min}$ & $10 \mathrm{~min}$ & & & \\
\hline ON & $1 \mathrm{~min}$ & $5 \mathrm{~min}$ & $10 \mathrm{~min}$ & & & \\
\hline OFF & $10 \mathrm{~min}$ & $10 \mathrm{~min}$ & $10 \mathrm{~min}$ & & & \\
\hline ON & $1 \mathrm{~min}$ & $5 \mathrm{~min}$ & $10 \mathrm{~min}$ & & & \\
\hline OFF & $10 \mathrm{~min}$ & $10 \mathrm{~min}$ & $10 \mathrm{~min}$ & & & \\
\hline
\end{tabular}

Note: Cyclical tests were conducted at $2.5 \mathrm{GPM}, 900 \mathrm{CFM}$, and $130^{\circ} \mathrm{F}$.

Field testing was used to supplement the laboratory testing where applicable. This project monitored five homes with combi systems and monitoring equipment installed for previous studies. Set point temperature modulation was tested in these homes. The impact on system efficiency and capacity was analyzed for a one-time reduction in set point temperature. An analysis of the data prior to and after the set point reduction determined the potential impact on outdoor reset temperature controls.

\subsection{Equipment}

The test laboratory was equipped with a comprehensive and accurate monitoring system utilizing high-precision instruments (Table 3). A Campbell Scientific model CR-3000 data logger was programmed to measure instrument outputs and record processed data at specified intervals. A propagation of errors method using the uncertainties of individual instruments for typical operating conditions was used to estimate an uncertainty of $2 \%$ for the calculated hot water energy output and an uncertainty of $2.5 \%$ for the system efficiency. In the laboratory, three identical sets of monitoring systems were used for tests on seven different heating plants using a single AHU (Table 4). Figure 1 includes photos of some of the systems installed in the laboratory. 
Table 3. Laboratory Instrumentation Equipment

\begin{tabular}{|c|c|c|c|c|}
\hline Measurement & Sensor Type & Resolution & Precision & Range \\
\hline $\begin{array}{c}\text { Water Volume } \\
\text { Flow Rate }\end{array}$ & $\begin{array}{c}\text { Nutating disk flow } \\
\text { meter }\end{array}$ & 198.4 pulses/gal & $2 \%$ of reading & $0.5-25 \mathrm{GPM}^{*}$ \\
\hline $\begin{array}{l}\text { Natural Gas } \\
\text { Volume }\end{array}$ & $\begin{array}{l}\text { Diaphragm meter, } \\
\text { with pulse output }\end{array}$ & 40 pulses $/ \mathrm{ft}^{3}$ & $0.3 \%$ of reading & $0-250$ CFM \\
\hline $\begin{array}{c}\text { Water } \\
\text { Temperatures }\end{array}$ & $\begin{array}{l}\text { Matched pair of } \\
\text { immersion RTDs }\end{array}$ & $0.002^{\circ} \mathrm{F}$ at $140^{\circ} \mathrm{F}$ & $\begin{array}{c}\text { 1/10 DIN: } 0.03^{\circ} \mathrm{F} \text { at } \\
32^{\circ} \mathrm{F}\end{array}$ & $-148^{\circ}$ to $752^{\circ} \mathrm{F}$ \\
\hline $\begin{array}{l}\text { Electric } \\
\text { Energy }\end{array}$ & Watt transducer & 0.02 Watts & $0.2 \%$ of reading & $0-1,000$ watts \\
\hline $\begin{array}{c}\text { Air } \\
\text { Temperature }\end{array}$ & Thermocouple array & $0.03^{\circ} \mathrm{F}$ at $140^{\circ} \mathrm{F}$ & $\begin{array}{c}\text { Greater of } 1.8^{\circ} \mathrm{F} \text { and } \\
0.75 \% \text { of reading }\end{array}$ & $-454^{\circ}$ to $725^{\circ} \mathrm{F}$ \\
\hline
\end{tabular}

* The meter measures flow rates lower than $0.5 \mathrm{GPM}$, but the precision decreases for flow rates outside the specified range.

Table 4. Laboratory-Tested Combi Equipment

\begin{tabular}{c|c|c}
\hline Equipment Type & Manufacturer & Model \\
\hline Condensing SWH & AO Smith & Vertex \\
\hline Condensing SWH & American & Polaris \\
\hline Condensing SWH & HTP & Phoenix \\
\hline Condensing TWH* & Rinnai & 98Lsi \\
\hline Hybrid Condensing TWH & Grand Hall & Eternal \\
\hline Condensing Boiler & Navien & Combi Boiler \\
\hline Condensing Boiler & Rinnai & Q175C \\
\hline Hydronic AHU & Enerzone & XAH 70VS-X13-4R-PT \\
\hline
\end{tabular}

* Tankless water heater

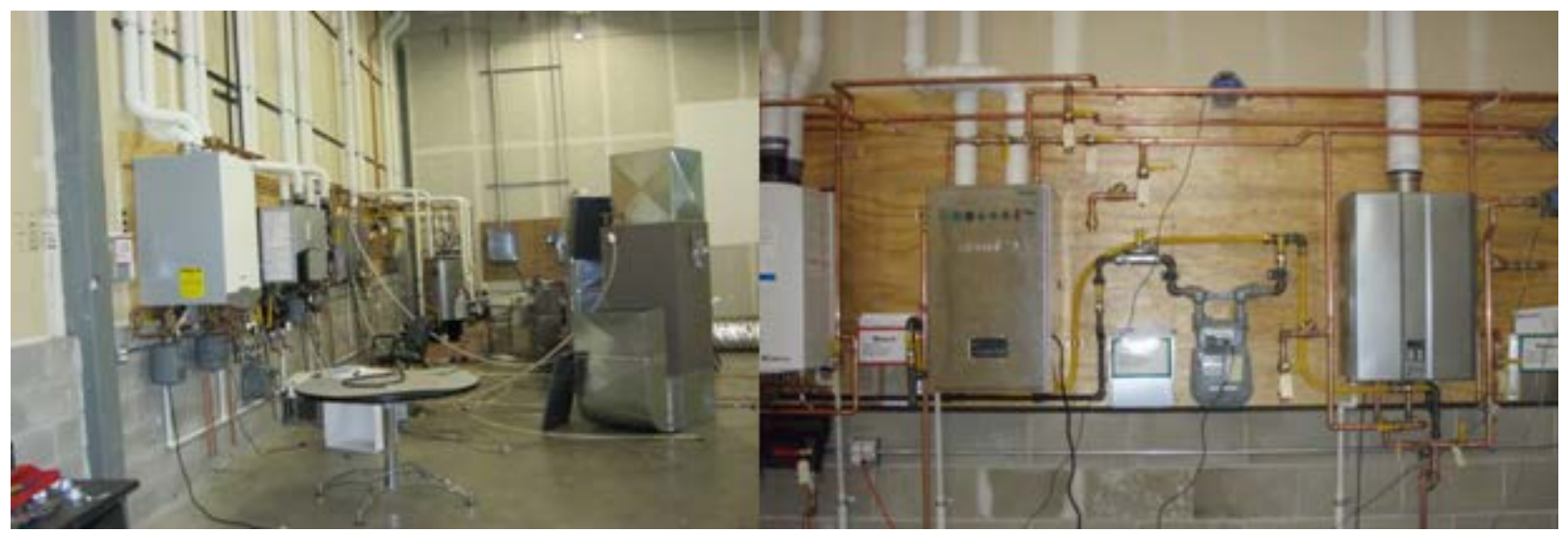

Figure 1. Photos of test laboratory with combi system installations 
The combi system field monitoring package included the same energy input and energy output instruments as those used in the test laboratory (Table 3). The impact of the control change on energy use was computed from a comparison of the input versus output regressions analysis. This is described in the following section. Table 5 describes the combi equipment and loads of the five test sites.

Table 5. Field Monitoring Test Sites

\begin{tabular}{|c|c|c|c|c|c|}
\hline \multirow{2}{*}{$\begin{array}{c}\text { Site } \\
\text { Number }\end{array}$} & \multicolumn{2}{|c|}{ Combi Appliance } & \multirow{2}{*}{$\begin{array}{c}\text { Calc Load* } \\
(\text { Btu/h) }\end{array}$} & \multirow{2}{*}{$\begin{array}{c}\text { Number of } \\
\text { Showers }\end{array}$} & \multirow{2}{*}{$\begin{array}{l}\text { Number } \\
\text { of People }\end{array}$} \\
\hline & Heating Plant & AHU & & & \\
\hline 1027 & Polaris & Enerzone & 38,774 & 2 & 4 \\
\hline 1031 & Polaris & Enerzone & 38,260 & 2 & 1 \\
\hline 1049 & Eternal & Enerzone & 36,277 & 2 & 5 \\
\hline 1056 & Phoenix & Enerzone & 26,112 & 1 & 1 \\
\hline 1070 & Eternal & Enerzone & 29,111 & 1 & 1 \\
\hline
\end{tabular}

Note: Calc Load was determined from the field measured data 


\section{Analysis}

\subsection{Laboratory Tests}

Laboratory testing used test data from a previous NorthernSTAR project (Schoenbauer et al. 2012) and new test data. New data consisted of a series of steady-state and cyclical tests (Table 1 and Table 2). The system energy input, output, and efficiency were computed for each test from direct measurements of water flow rates, water temperatures, and gas use. The laboratory test data were used with results from the NorthernSTAR field monitoring project (Schoenbauer et al. 2014) to compute the seasonal system efficiency and annual energy use for four control strategies. In general, empirical field data were used to create seasonally dependent space- and water-heating load models. Laboratory data were used to calculate the system performance and energy use for the model loads over a full year.

Daily average method. Daily average load and system performance relationships were used to estimate the annual energy use and efficiency for combi systems using four control methods. The first two strategies used a single space-heating operating point (fixed airflow rate, water flow rate, and set point temperature) for a $140^{\circ} \mathrm{F}$ set point temperature (SP 140); for the second the set point was optimized for the design space-heating condition (optimized SP). These were compared to combi performance with a set point temperature reset control (SP reset) and a full modulating control that varied the set point temperature, water flow, and airflow rates (full modulation). A four-step process was used to estimate the annual efficiency of each control operation:

1. Characterize the combi system capacity and efficiency.

2. Calculate the daily space-heating energy use based on the outside air temperature and heating load relationship and the combi system performance.

3. Calculate the daily DHW energy use based on the DHW use and the temperature set point required for space heating.

4. Sum the annual energy use and compute annual efficiencies.

A more detailed description of each step follows:

Characterize the system operation. Return water temperature had the greatest impact on system efficiency (Schoenbauer et al. 2012). The characteristics of the AHU, both design (coil size and effectiveness) and operation (flow rates and water temperatures), determined the return water temperature. One high-performance AHU was selected for use in this study. The AHU was tested previously in the laboratory and used with every field installation. The large coil size and good component design led to a very high heat transfer effectiveness. Using an AHU with a smaller output (i.e., smaller water temperature drop) or choosing nonoptimized flow rates would have resulted in lower system efficiencies.

For the previous field monitoring project the combi systems were installed with a constant set point temperature of $140^{\circ} \mathrm{F}$, constant hydronic AHU airflow rate, and constant water flow rate adjusted to achieve a return water temperature no higher than $105^{\circ} \mathrm{F}$ (typically $2-3 \mathrm{GPM}$ ). The operating characteristics for the base case of this analysis were selected to mimic that setup: combi heating plant set point $=140^{\circ} \mathrm{F}$, airflow rate $=900 \mathrm{CFM}$, and water flow rate $=2.5 \mathrm{GPM}$. 
The second case also used constant heating plant set point temperature, airflow rate (900 CFM), and water flow rate $(2.5 \mathrm{GPM})$. The difference was that the heating plant set point temperature was optimized for the design space-heating load. The set point temperature was specified to be the lowest value (and highest efficiency) that would provide the required space-heating output for outdoor air design temperature conditions.

The other two strategies used variable control methods. The supply water set point reset control method allowed the combi system to operate at various set point temperatures. The combi systems were optimized for the design load. The space-heating performance conditions were determined by changing only the set point temperature. Table 6 shows the bins for an AHU water flow rate of 5 GPM and airflow rate of 900 CFM for the Eternal water heater.

Table 6. Eternal Water Heater-Based Combi System Performance Bins for Operation at 5 GPM and 900 CFM

\begin{tabular}{c|c|c|c}
\hline $\begin{array}{c}\text { Space-Heating } \\
\text { Output } \\
(\mathbf{B t u} / \mathbf{h})\end{array}$ & $\begin{array}{c}\text { Supply Water } \\
\text { Temperature } \\
\left({ }^{\circ} \mathbf{F}\right)\end{array}$ & $\begin{array}{c}\text { Return Water } \\
\text { Temperature } \\
\left({ }^{\circ} \mathbf{F}\right)\end{array}$ & $\begin{array}{c}\text { System } \\
\text { Efficiency } \\
(\mathbf{\%})\end{array}$ \\
\hline $\mathbf{6 8 , 8 1 0}$ & 140 & 113 & 86.6 \\
$\mathbf{6 3 , 4 3 7}$ & 135 & 110 & 90.2 \\
$\mathbf{5 9 . 6 2 5}$ & 130 & 106 & 91.8 \\
$\mathbf{5 5 , 0 3 2}$ & 125 & 103 & 92.3 \\
$\mathbf{5 0 , 4 3 9}$ & 120 & 100 & 92.8 \\
\hline
\end{tabular}

The full modulation control method allowed the combi system to operate at different airflow and water flow rates as well as water set point temperatures. A matrix of heating system performance was created to represent the expected range of combi system operating conditions. Laboratory tests were used to determine the combi system output capacity and efficiency for each condition or set of operating parameters (set point temperature, water flow rate, and airflow rate), which determined the output capacity and the system efficiency. Varying all three parameters increased the flexibility of the system by allowing for a wider range of AHU capacities and increased heating plant efficiency.

Figure 2 shows the operating conditions for the hybrid water heater-based combi system. With the SP 140 control method, the system had only one operating condition over the full range of operation. The reset SP and full modulation control strategies provided multiple operating conditions with increased efficiency as the operating capacity was reduced. For both control methods the analysis methodology used a fixed number of conditions to reduce the number of laboratory test conditions. In practice, set point temperature, water flow rate, and airflow rate could be continuously variable. This variability would increase the flexibility of the system, improving the fit between system capacity and daily load. However, the fixed conditions selected for this analysis provide a good representation of performance, because the change in efficiency is only $0.5 \%$ for $5^{\circ} \mathrm{F}$ set point changes from $130^{\circ}$ to $120^{\circ} \mathrm{F}$ and $1.6 \%$ from $135^{\circ}$ to $130^{\circ} \mathrm{F}$. 


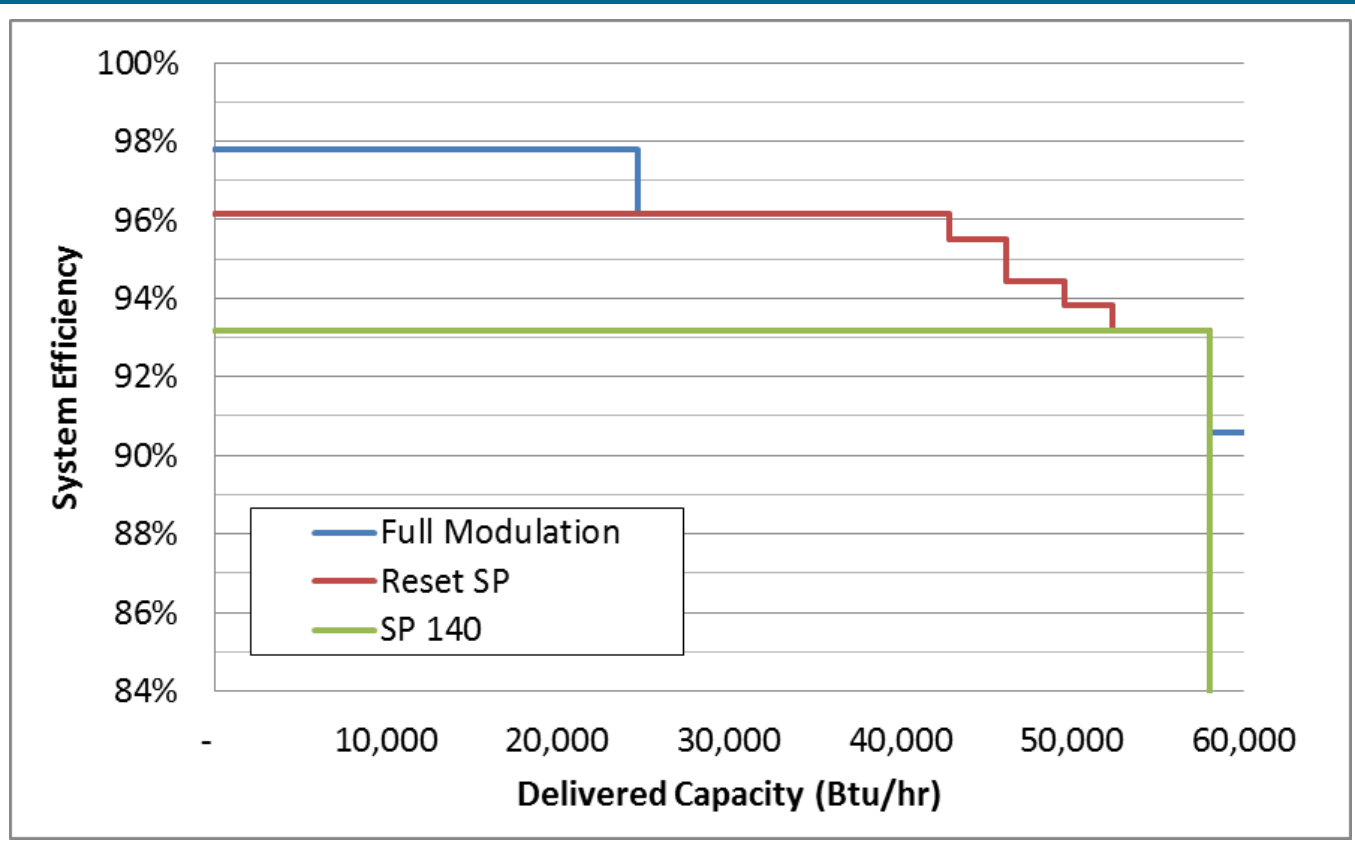

Figure 2. Combi system space-heating operating capacity: Eternal hybrid water heater

Calculate space-heating use. The daily space-heating input was calculated by matching the combi system performance stages (Step 1) to the daily space-heating load. The home's spaceheating load was computed from a linear relationship with outside temperature. Results from a utility bill study were used to determine space-heating loads for three characteristic categories of homes in a heating-dominated climate (Minneapolis, Minnesota). This study was used solely to select heating load profiles representative in Minnesota. Utility billing data were analyzed for 63 combi system installations and the results were used to determine the design loads. Low-, medium-, and high-load homes were defined. The design heating load, design outdoor temperature, and balance point temperature define the relationship between the outside temperature and the space-heating load (Table 7 and Table 4). The homes with design loads lower than $30,000 \mathrm{Btu} / \mathrm{h}$ (the 15 th percentile) were used to define the low-load category. Those had an average design load of 25,000 Btu/h. The homes with loads higher than 40,000 (the 80th percentile) had an average design load of 49,300, which was used as the high-load case. Sixtyfive percent of the homes analyzed had design loads of 30,000-40,000 Btu/h. The average load of $30,900 \mathrm{Btu} / \mathrm{h}$ for these homes was used as the medium load. The average balance point temperature for all the homes $\left(63^{\circ} \mathrm{F}\right)$ was used for all three load levels, and the outdoor air design load temperature was set equal to the value specified for Minneapolis, Minnesota $\left(-18^{\circ} \mathrm{F}\right)$.

Table 7. Space-Heating Characteristics for Binned Analysis

\begin{tabular}{c|c|c|c}
\hline House Category & $\begin{array}{c}\text { Design Space- } \\
\text { Heating Load } \\
(\mathbf{B t u} / \mathbf{h})\end{array}$ & $\begin{array}{c}\text { Design Outdoor } \\
\text { Air Temperature } \\
\left({ }^{\circ} \mathbf{F}\right)\end{array}$ & $\begin{array}{c}\text { Balance Point } \\
\text { Temperature } \\
\left({ }^{\circ} \mathbf{F}\right)\end{array}$ \\
\hline Low Load & 25,000 & -18 & 63 \\
Medium Load & 34,900 & -18 & 63 \\
High Load & 49,300 & -18 & 63 \\
\hline
\end{tabular}




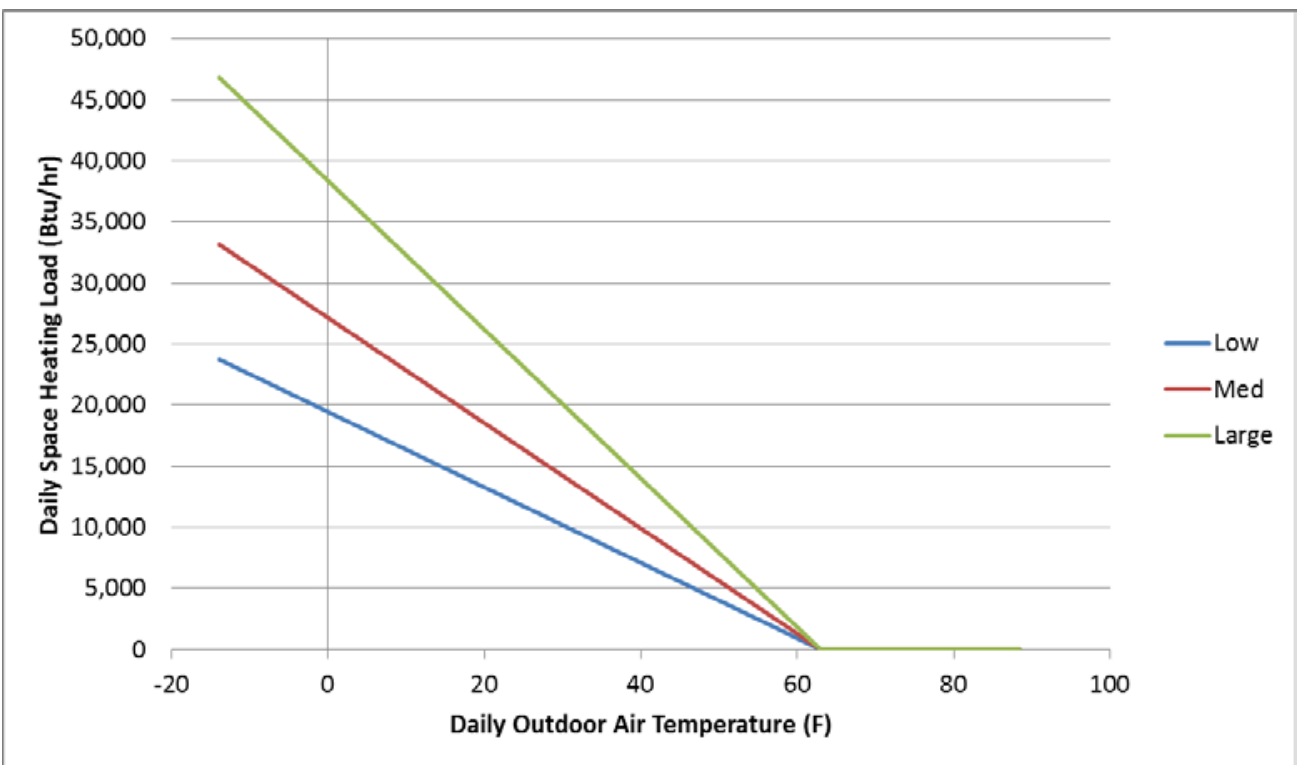

Figure 3. Daily outside air temperature to space-heating load relationships for three homes

Each day was matched to a combi system stage as defined in Step 1. For each day the spaceheating load was multiplied by 1.20 to account for setback recovery and a safety factor. The operating mode that provided the highest system efficiency while meeting this need was assigned to the day. The combi system supply water set point was required to be at least $120^{\circ} \mathrm{F}$ as a minimum value for DHW use. Laboratory cycling and steady-state test data were used to determine the total daily output energy and efficiency for each day.

Calculate DHW use. The DHW load was treated separately from the space-heating load. Daily DHW use in each home has significant variance, typically ranging from 0 to twice the daily average. Seasonal DHW use profiles were developed in the previous field study to show average use and seasonality impacts (Schoenbauer et al. 2014). The profiles from 19 homes were divided into high (80 gallons per day [GPD] average), medium (35 GPD average), and low (12 GPD average) use (Figure 4). The median use home of each group was selected for the analysis. The DHW energy use was estimated using field data collected from a high-efficiency water heating field monitoring project (Schoenbauer et al. 2010) and the standby testing previously conducted on combi systems in the laboratory (Schoenbauer et al. 2012).

Sum the annual use. Annual performance was determined by summing the total energy output (space heating and DHW) and input for each day. The annual efficiency was computed from the ratio of the annual energy output to input. 


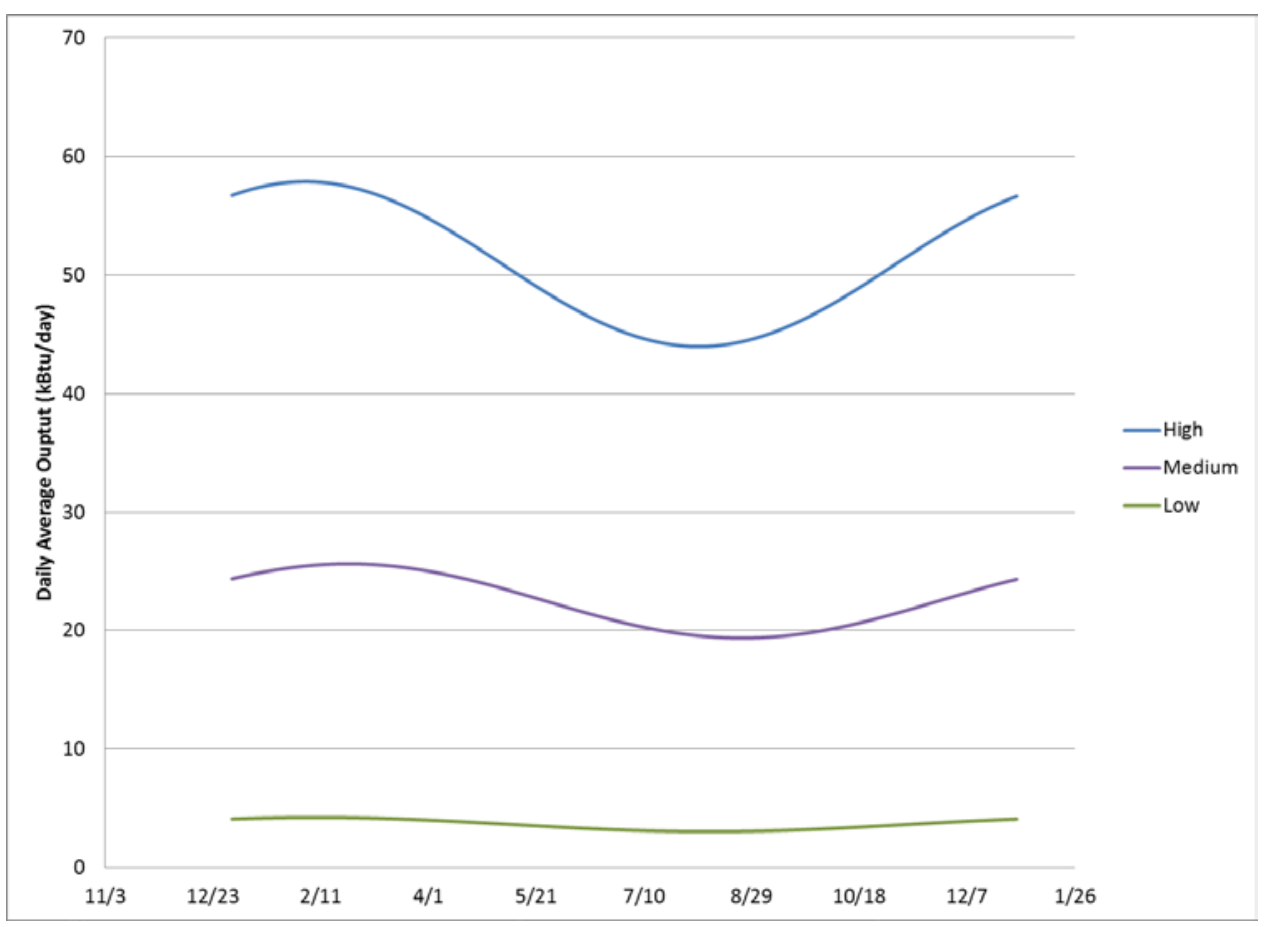

Figure 4. Seasonal DHW use profiles

\subsection{Field Tests}

\subsubsection{Set Point Reduction}

The field test part of the project compared the efficiencies of combi systems as they were installed in the previous field study to those of the same systems with a reduced set point temperature. The annual energy use and efficiencies were computed from the sum of the modeled energy load and use for each day in the year (Schoenbauer et al. 2012). Regressions of monitored daily average data established a linear balance point relationship between the spaceheating load and the outside temperature (Figure 5). The seasonal variation in the inlet water temperature and the relationship between the inlet water temperature and DHW load were used to determine the DHW load for each day of the year (Figure 4).

These load curves were used with the outside air temperature from the Minneapolis/St. Paul Typical Meteorological Year 3 weather data set to calculate the space- and water-heating loads for each day. Regressions of the monitored daily average data established the linear relationship between combi system energy input and output. The loads were assumed to be equal to the sum of the system energy output. Loads and input to output relationships were split into groups: DHW only and space heating and DHW combined. The previous study found that for days with both DHW and space-heating loads, the input/output relationship was not significantly affected by the fraction of the load that was due to DHW or space heating. Consequently, the sum of the DHW and space-heating loads was used with the daily linear input output relationships to determine the daily energy use. Daily energy use and loads were summed to determine annual use, consumption, and efficiency. 


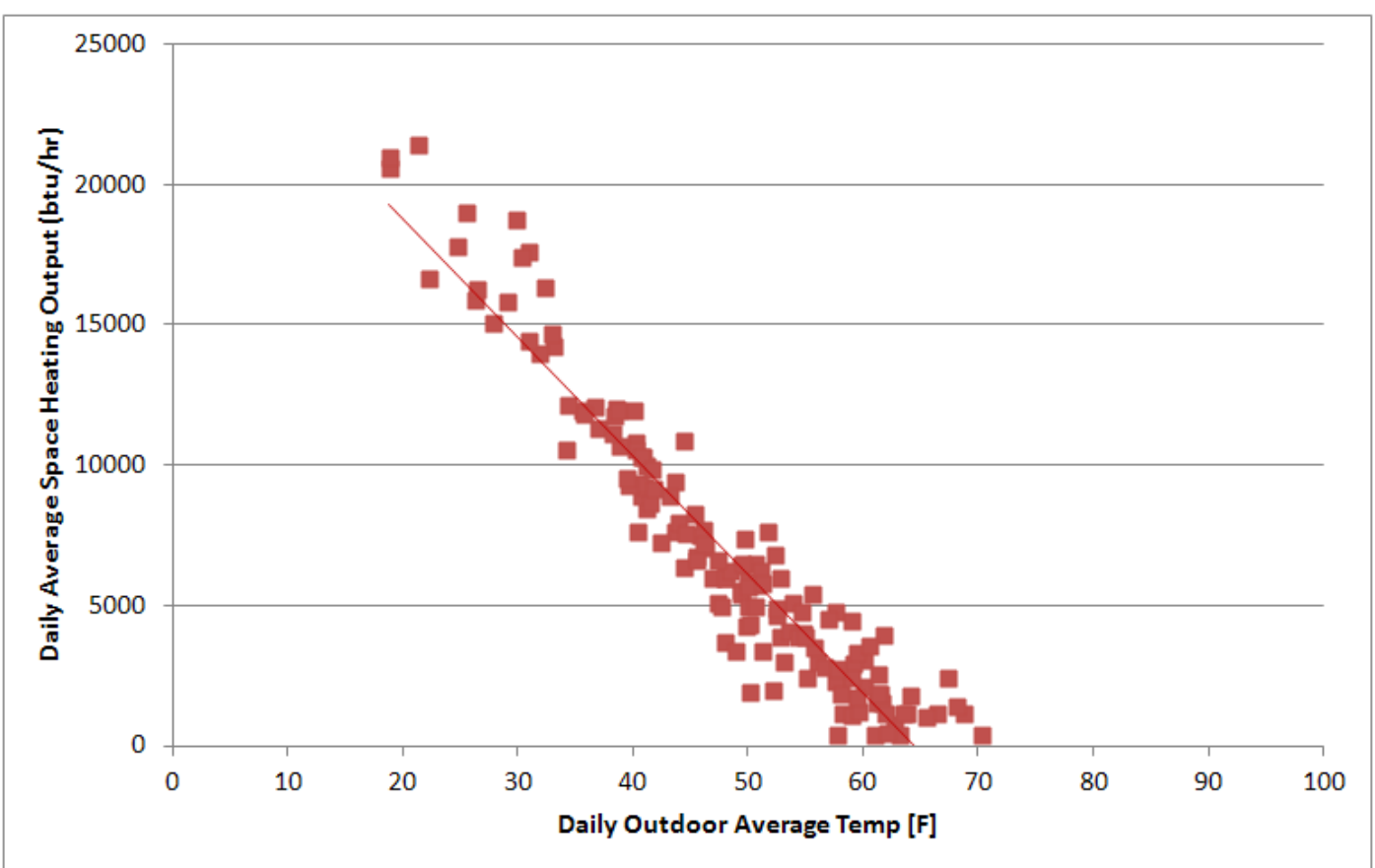

Figure 5. Daily space-heating load by outdoor air temperature for a field site

After monitoring for the previous project was complete, the water temperature set point was reduced for five of the test sites. Data collected at these sites were used to create new system energy input/output performance relationships; these were applied to the same space-heating and DHW load profiles. The new efficiency and energy use data were compared to the system as operated during the previous project to determine the savings potential of set point temperature reduction.

\subsubsection{Domestic Hot Water Priority}

DHW priority controls the operation of the combi system during times when the system has simultaneous DHW and space-heating loads. This control strategy gives priority to DHW loads. For example, if hot water is being used for a shower when the house thermostat calls for heat, a flow control valve in the combi system prevents (or for some systems limits) the space-heating flow rate system until the DHW flow is no longer sensed. Additionally, if a space-heating call is being met and a hot water fixture is turned on, the flow controllers stop (or reduce) flow to the hydronic AHU and prioritize the DHW.

The DHW priority control was used by the five boiler-based combi systems installed in the previous field monitoring project. Data from that project were used to determine whether DHW priority can improve occupant comfort and reduce peak loads on the system.

Occupant comfort was assessed by analyzing the delivered water and air temperatures during simultaneous DHW and space-heating events for systems with and without DHW priority. Reductions and increases in delivered air and water temperatures were measured as simultaneous use starts or stops. Comparing the firing rates of systems with and without DHW priority showed the impact of this control on the separation of DHW and space-heating loads on sizing criteria. 


\section{Results and Discussion}

\subsection{Laboratory Tests}

The increased efficiency and energy savings were computed using the daily average analysis results for the optimized set point (optimized SP), set point reset (SP reset) and full modulation control strategies compared to a combi system operating with a set point of $140^{\circ} \mathrm{F}$ (SP 140). These strategies improved the efficiencies of combi systems with the SWHs and hybrid water heaters, but were less effective for the TWH- and boiler-based systems.

The hydronic AHU return water temperature had the greatest impact on space-heating efficiency. The control methods achieved lower return temperatures and higher annual operating efficiencies by reducing the set point temperature, increasing the airflow rate, or decreasing the water flow rate.

Figure 6 shows the relationship between return water temperature and space-heating efficiency for the Vertex SWH tested at various water temperatures, airflow rates, and water flow rates. There is a consistent trend of increasing efficiency with decreasing return water temperature. The return water temperature was a function of several other parameters (i.e., water flow, airflow, and set point temperature); these other parameters independently and significantly affected efficiency. For example, if a system were operated at two operating conditions, both of which had a return water temperature of $110^{\circ} \mathrm{F}$, the same efficiency would be expected even if the flow rates were different. The laboratory test results, which are shown for the Vertex SWH in Figure 6 and Table 8 , were used to select the combi system operating condition that defined the daily performance of the combi system.

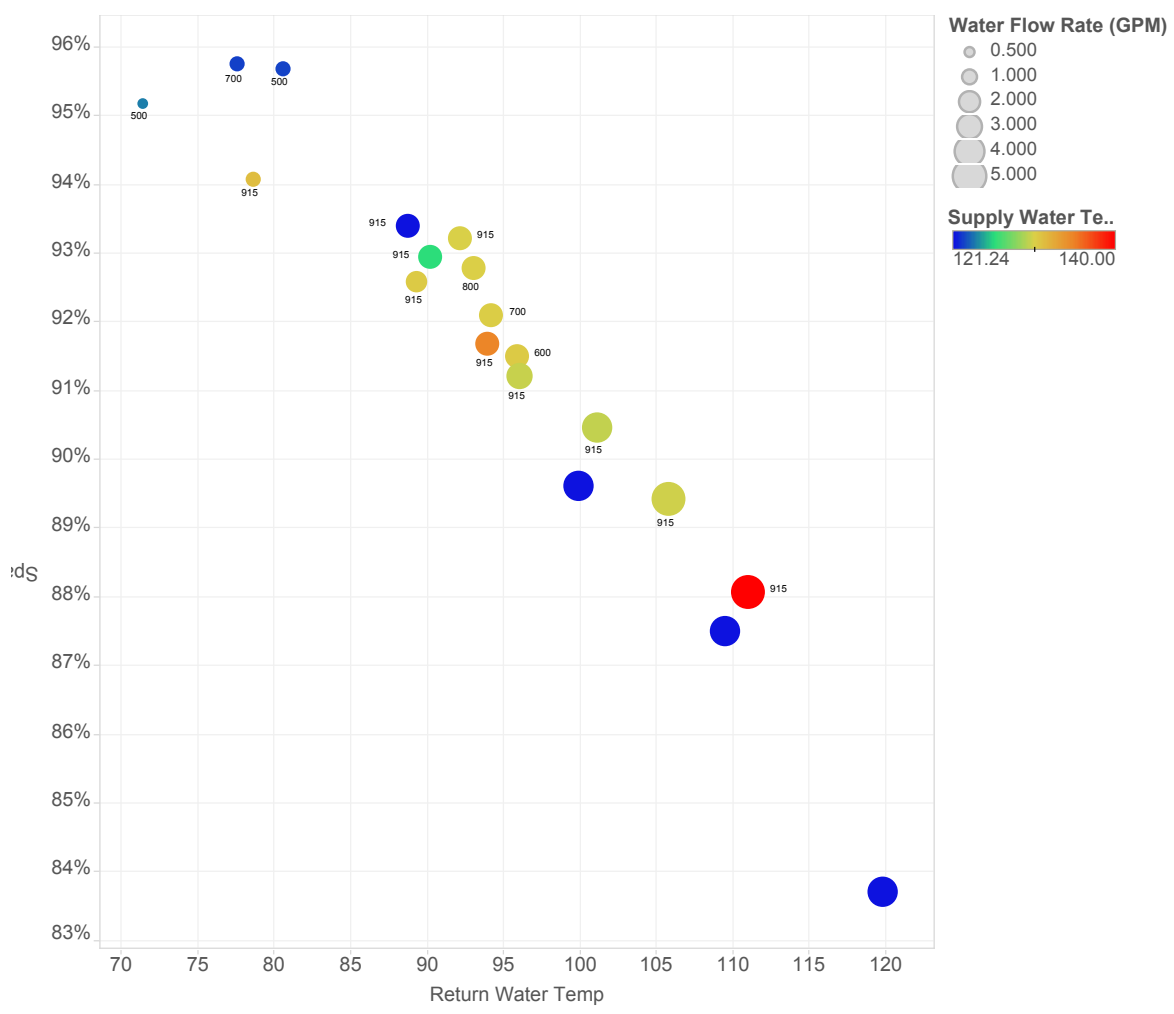

Figure 6. Steady-state space-heating efficiency for the Vertex SWH 
Table 8. Steady-State Space Heating Laboratory Results for the Vertex SWH

\begin{tabular}{|c|c|c|c|c|c|c}
\hline Test ID & $\begin{array}{c}\text { Flow Rate } \\
\text { (GPM) }\end{array}$ & $\begin{array}{c}\text { Airflow } \\
\text { (CFM) }\end{array}$ & $\begin{array}{c}\text { Set Point } \\
\text { Temperature } \\
(\mathbf{P} \mathbf{F})\end{array}$ & $\begin{array}{c}\text { Return Water } \\
\text { Temperature } \\
\left({ }^{\circ} \mathbf{F}\right)\end{array}$ & $\begin{array}{c}\text { Output } \\
\text { (Btu/h) }\end{array}$ & $\begin{array}{c}\text { Efficiency } \\
\mathbf{( \% )}\end{array}$ \\
\hline Test 1 & 2.5 & 900 & 140 & 95.3 & 52,736 & 90.3 \\
\hline Test 2 & 2.5 & 900 & 135 & 94.0 & 50,975 & 91.7 \\
\hline Test 3 & 2.5 & 900 & 130 & 92.2 & 47,228 & 93.2 \\
\hline Test 4 & 2.5 & 900 & 125 & 90.3 & 45,425 & 92.7 \\
\hline Test 5 & 2.5 & 900 & 120 & 88.8 & 41,607 & 93.4 \\
\hline Test 6 & 5 & 900 & 130 & 105.8 & 61,308 & 89.4 \\
\hline Test 7 & 4 & 900 & 130 & 101.1 & 56,100 & 90.5 \\
\hline Test 8 & 3 & 900 & 130 & 96.1 & 50,668 & 91.2 \\
\hline Test 9 & 2 & 900 & 130 & 89.3 & 43,338 & 92.6 \\
\hline Test 10 & 1 & 900 & 130 & 78.6 & 26,193 & 94.1 \\
\hline Test 11 & 2.5 & 800 & 130 & 93.1 & 46,166 & 92.8 \\
\hline Test 12 & 2.5 & 700 & 130 & 94.3 & 44,869 & 92.1 \\
\hline Test 13 & 2.5 & 600 & 130 & 95.9 & 43,188 & 91.2 \\
\hline Extra 1 & 1 & 500 & 120 & 80.6 & 21,819 & 95.7 \\
\hline Extra 2 & 0.5 & 500 & 120 & 77.5 & 13,524 & 95.2 \\
\hline Extra 3 & 1 & 500 & 120 & 71.4 & 23,385 & 95.7 \\
\hline
\end{tabular}

Note: The set point temperature is not the same as the delivered water temperature. With SWHs the delivery temperature is typically below the set point because of the dead band on stored water temperature.

The operating conditions were selected for each control method to provide the maximum efficiency for the necessary output capacity each day. This improved annual operating efficiencies (Figure 7) and reduced annual energy use (Table 9) for the set point temperature (SP reset) and flow rate modulation (full modulation) controls. The energy savings and controls are compared to the fixed capacity, constant set point combi system (SP 140). The base case (SP 140) used a water flow rate of $2.5 \mathrm{GPM}$, an airflow of $900 \mathrm{CFM}$, and a set point temperature of $140^{\circ} \mathrm{F}$. The base case was consistent with the most common operating conditions for the field installations. This configuration was the point at which the return water temperature from the AHU was lower than $105^{\circ} \mathrm{F}$ and the air temperature was at least $115^{\circ} \mathrm{F}$ - the parameters for the field study optimization. In addition to the base case and the control cases, a single-stage combi system with the optimized set point water temperature was analyzed (optimized SP). All cases assumed the use of the same high-performance AHU. Applying this analysis to a smallercapacity, less-expensive AHU would have increased the savings for the reset and fully modulating control strategies. 


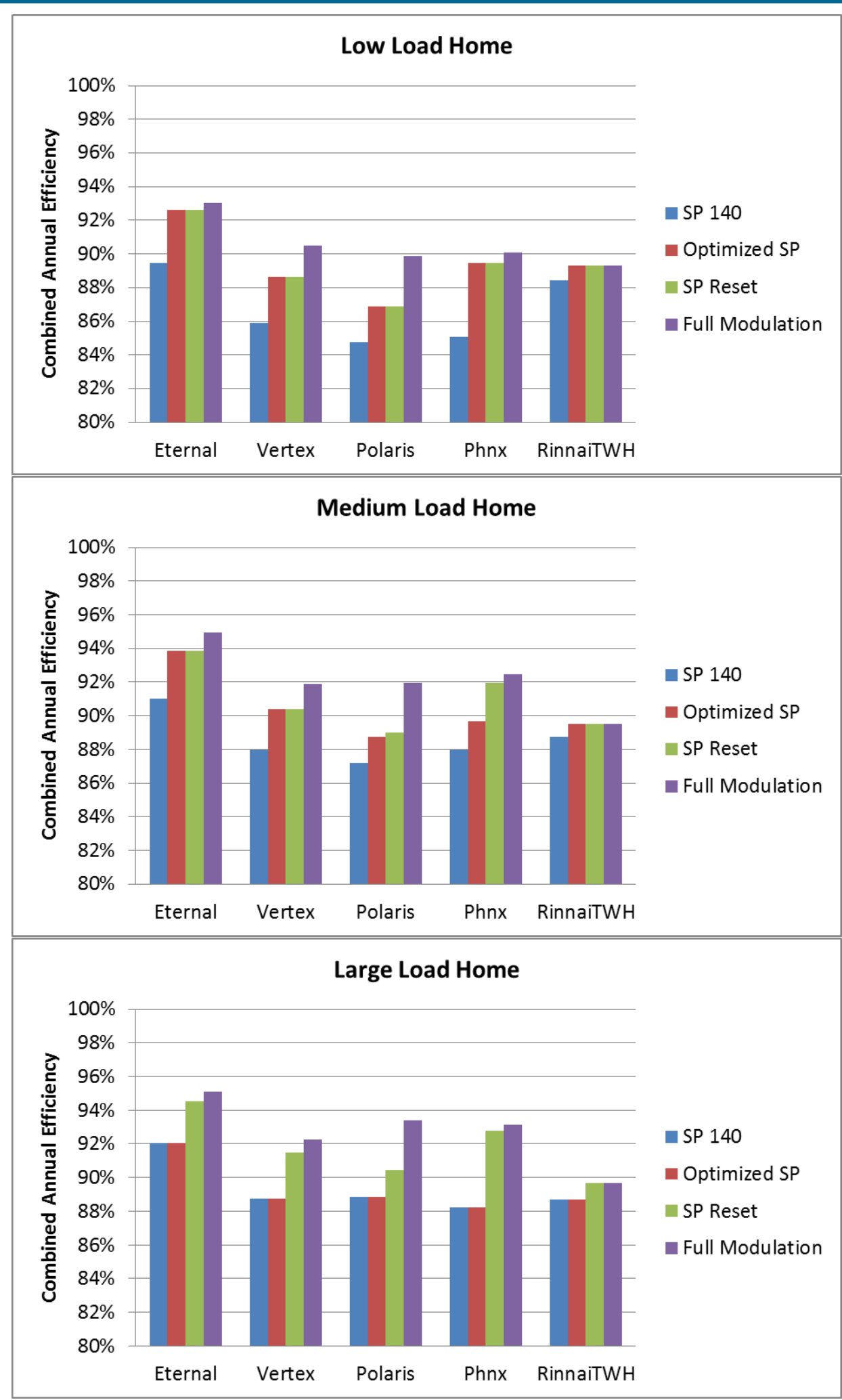

Note: These efficiencies are calculated based on laboratory testing and load data measured in the field.

Figure 7. Combined (space and DHW) efficiencies for both control strategies 
Table 9. Energy Use and Savings from Control Strategies

\begin{tabular}{|c|c|c|c|c|c|c|}
\hline \multirow{3}{*}{ Control Method } & & \multicolumn{3}{|c|}{ SWHs } & \multirow{2}{*}{$\begin{array}{c}\begin{array}{c}\text { Hybrid } \\
\text { Water } \\
\text { Heater }\end{array} \\
\text { Eternal }\end{array}$} & \multirow{2}{*}{$\begin{array}{c}\text { TWH } \\
\text { Rinnai }\end{array}$} \\
\hline & & Phoenix & Vertex & Polaris & & \\
\hline & & \multicolumn{5}{|c|}{ Low-Load Home } \\
\hline Base Case-SP 140 & $\begin{array}{l}\text { Energy use } \\
\text { (therms/year) }\end{array}$ & 643 & 637 & 645 & 611 & 618 \\
\hline Optimized SP & $\%$ saved & $4.9 \%$ & $3.0 \%$ & $2.4 \%$ & $3.4 \%$ & $1.0 \%$ \\
\hline SP Reset & $\%$ saved & $4.9 \%$ & $3.0 \%$ & $2.4 \%$ & $3.4 \%$ & $1.0 \%$ \\
\hline Full Modulation & $\%$ saved & $5.6 \%$ & $5.0 \%$ & $5.7 \%$ & $3.4 \%$ & $1.0 \%$ \\
\hline & & \multicolumn{5}{|c|}{ Medium-Load Home } \\
\hline Base Case-SP 140 & $\begin{array}{l}\text { Energy use } \\
\text { (therms/year) }\end{array}$ & 940 & 941 & 949 & 909 & 932 \\
\hline Optimized SP & $\%$ saved & $1.9 \%$ & $2.7 \%$ & $1.8 \%$ & $3.0 \%$ & $0.9 \%$ \\
\hline SP Reset & $\%$ saved & $4.3 \%$ & $2.7 \%$ & $2.1 \%$ & $3.0 \%$ & $0.9 \%$ \\
\hline Full Modulation & $\%$ saved & $4.8 \%$ & $4.2 \%$ & $5.2 \%$ & $4.1 \%$ & $0.9 \%$ \\
\hline & & \multicolumn{5}{|c|}{ High-Load Home } \\
\hline Base Case_-SP 140 & $\begin{array}{l}\text { Energy use } \\
\text { (therms/year) }\end{array}$ & 1403 & 1396 & 1394 & 1345 & 1396 \\
\hline Optimized SP & $\%$ saved & $0.0 \%$ & $0.0 \%$ & $0.0 \%$ & $0.0 \%$ & $0.0 \%$ \\
\hline SP Reset & $\%$ saved & $4.8 \%$ & $3.0 \%$ & $1.8 \%$ & $2.6 \%$ & $1.1 \%$ \\
\hline Full Modulation & $\%$ saved & $5.2 \%$ & $3.7 \%$ & $4.9 \%$ & $3.1 \%$ & $1.1 \%$ \\
\hline
\end{tabular}

The optimized SP control strategy produced greater savings for the low-load homes than for the high-load homes. The optimized SP control achieved $100 \%$ of the savings as that for the SP reset and greater than $75 \%$ of the savings as the full modulating controls in the low-load homes. In the medium-load homes the optimized SP control strategy produced an average of $85 \%$ of the savings for the SP reset control and $60 \%$ of the full modulation control. In the low- and mediumload homes the optimized SP control was often able to operate the system at or near the minimum set point temperature (typically $125^{\circ} \mathrm{F}$ or $120^{\circ} \mathrm{F}$ ).

Further optimization from this condition resulted in only minor savings. For high-load homes the optimized SP control had no added savings because the system set point had to be $140^{\circ} \mathrm{F}$ to satisfy design load conditions. In these cases further control (SP reset and full modulation) were able to further reduce the system capacity and increase efficiency on nondesign condition days. For example, for a low-load home with a Vertex-based combi using an optimized SP control, the system always operated at a $120^{\circ} \mathrm{F}$ set point (Table 8 Test 5) and an efficiency of $93.4 \%$. For the full modulation control the combi system would also be able to operate at lower capacity (test extra 1) with an efficiency of $95.7 \%$, resulting in a small boost in efficiency at low-capacity operation. For a high-load home the optimized SP system would always operate at a $140^{\circ} \mathrm{F}$ set point (Table 8 Test 1 ) with an efficiency of $90.3 \%$. The full modulation control allowed the combi system to reduce its capacity to the extra 1 operating mode and to increase the efficiency to $95.7 \%$. This increased range of operation and lower efficiency in the optimized SP case allowed for greater savings. 
The full modulation strategy always resulted in higher efficiencies and larger energy reductions than the set point control. The increased flexibility of airflow and water flow rate reductions allowed the system to operate at lower-capacity and higher-efficiency conditions than the temperature control alone. Set point temperature control allowed for reductions in space-heating output of $20 \%$ of the design load, which corresponded to an $8^{\circ} \mathrm{F}$ reduction in return water temperature. For the Vertex water heater, this return water temperature reduction corresponded to a $5.9 \%$ increase in efficiency. The full modulation control allowed for reductions in the spaceheating output capacity of up to $60 \%$ of design and an $18^{\circ} \mathrm{F}$ reduction in return water temperature, which increased efficiency up to $3.4 \%$ for the Vertex water heater.

\subsubsection{Tankless Water Heaters}

As previously mentioned, the control strategies were not as effective for the TWH- and boilerbased combi systems. The control strategies rely on reducing the operating output of the hydronic AHU as the space-heating load is reduced, which reduces the return water temperature and improves efficiency. The efficiency increase with reduced return water temperature was not as significant for the TWH- and boiler-based systems at low operating capacities. Figure 8 shows the impact of return water temperature on efficiency for the TWH. Efficiency for this unit peaked with return water temperatures of around $95^{\circ} \mathrm{F}$, and the relationship between return water and efficiency was inconsistent at temperatures lower than $100^{\circ} \mathrm{F}$. The operating points for the optimized combi system with constant set points (highlighted red in Figure 8) were either at or very near peak system efficiency, leaving little room for improvement for the SP reset and full modulation control methods. As shown by the TWH input to output relationship in Figure 9, at outputs lower than $43,000 \mathrm{Btu} / \mathrm{h}$ the TWH system had a significant change in the input output relationship, which corresponded to a reduced efficiency at lower output rates. A similar effect has been measured for TWHs installed for DHW performance, where efficiency decreased with firing rate (Schoenbauer et al. 2010). 


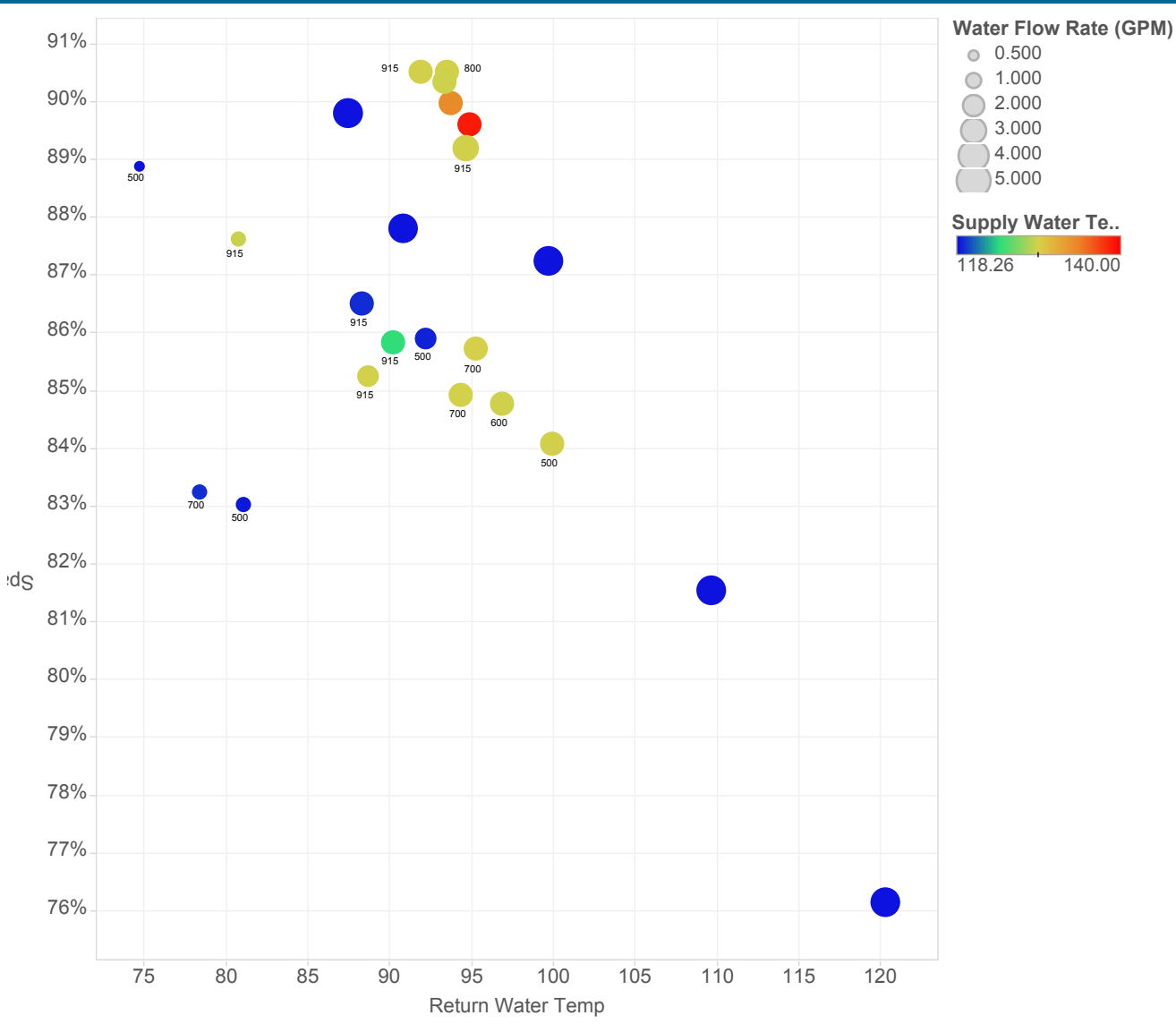

Figure 8. Space-heating efficiency versus return water temperature for the Rinnai TWH

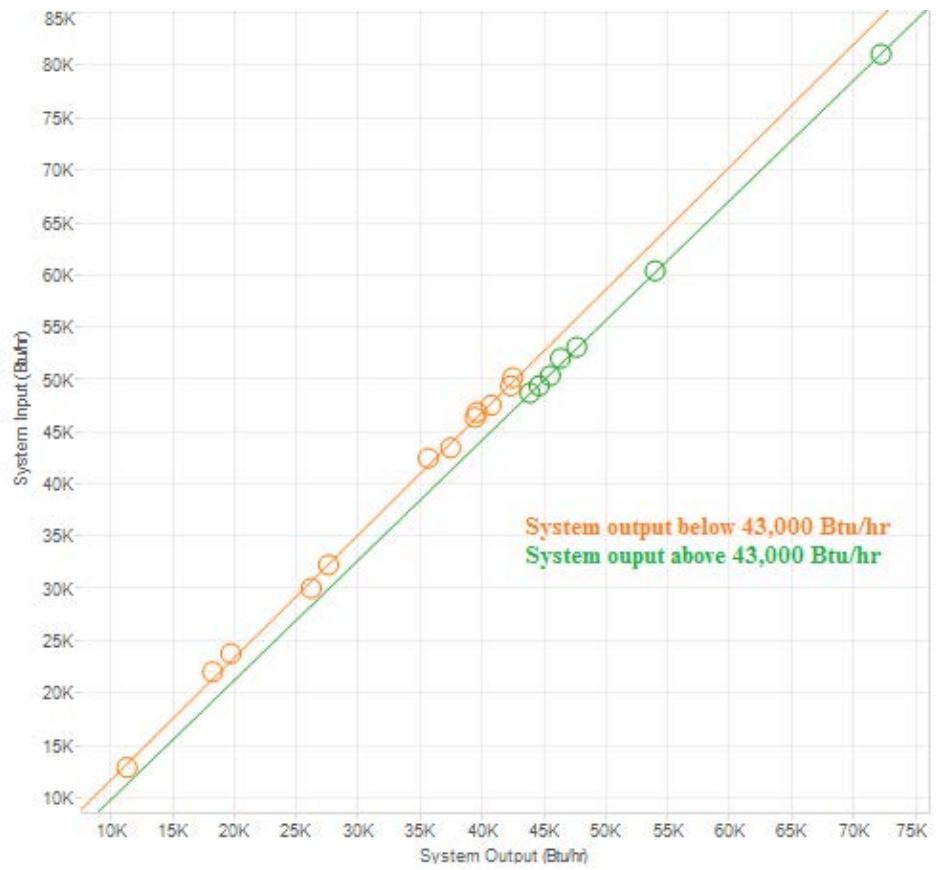

Figure 9. TWH space-heating input versus output relationship 


\subsubsection{Boilers}

Combination boilers used with forced-air systems had a slightly different plumbing configuration than combi systems with water heaters (Figure 10). The boiler-based systems had a primary/secondary loop configuration. The manufacturers included the primary loop so the boiler could control the water flow rate and temperatures inside the boiler. If the water flow rate through the AHU (the secondary loop) was lower than the flow rate in the primary loop (through the boiler), some supply water from the boiler bypassed the AHU, which increased the return water temperature. The primary/secondary loop plumbing configuration overrode the benefit of reducing the return water temperature. This plumbing configuration impact has been observed for condensing boilers in other research studies (Arena 2010; Butcher 2006). Figure 11 shows the results from the steady-state testing. The results suggest that an optimized control strategy might be identifiable. This strategy would not simply target the lowest possible return water temperature from the AHU. An ideal boiler control strategy would work with the internal primary loop control to achieve the lowest return water temperature in the primary loop, leading to a higher efficiency. This is apparently achieved from AHU water flow rates that match the internal boiler flow rates, which may be higher than flow rates used in a water heater-based system, and lower boiler set point temperatures.

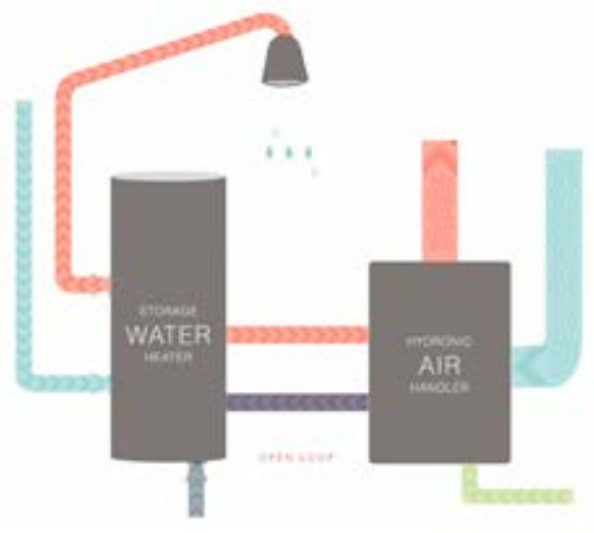

Water Heater based Combi

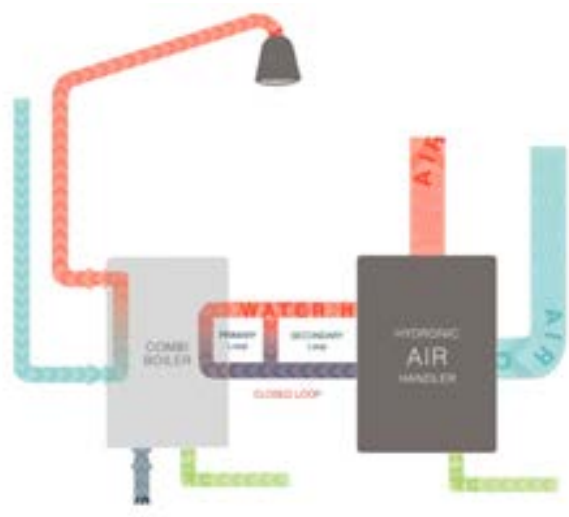

Boiler based Combi

Figure 10. Water heater and boiler-based combi system plumbing configurations 


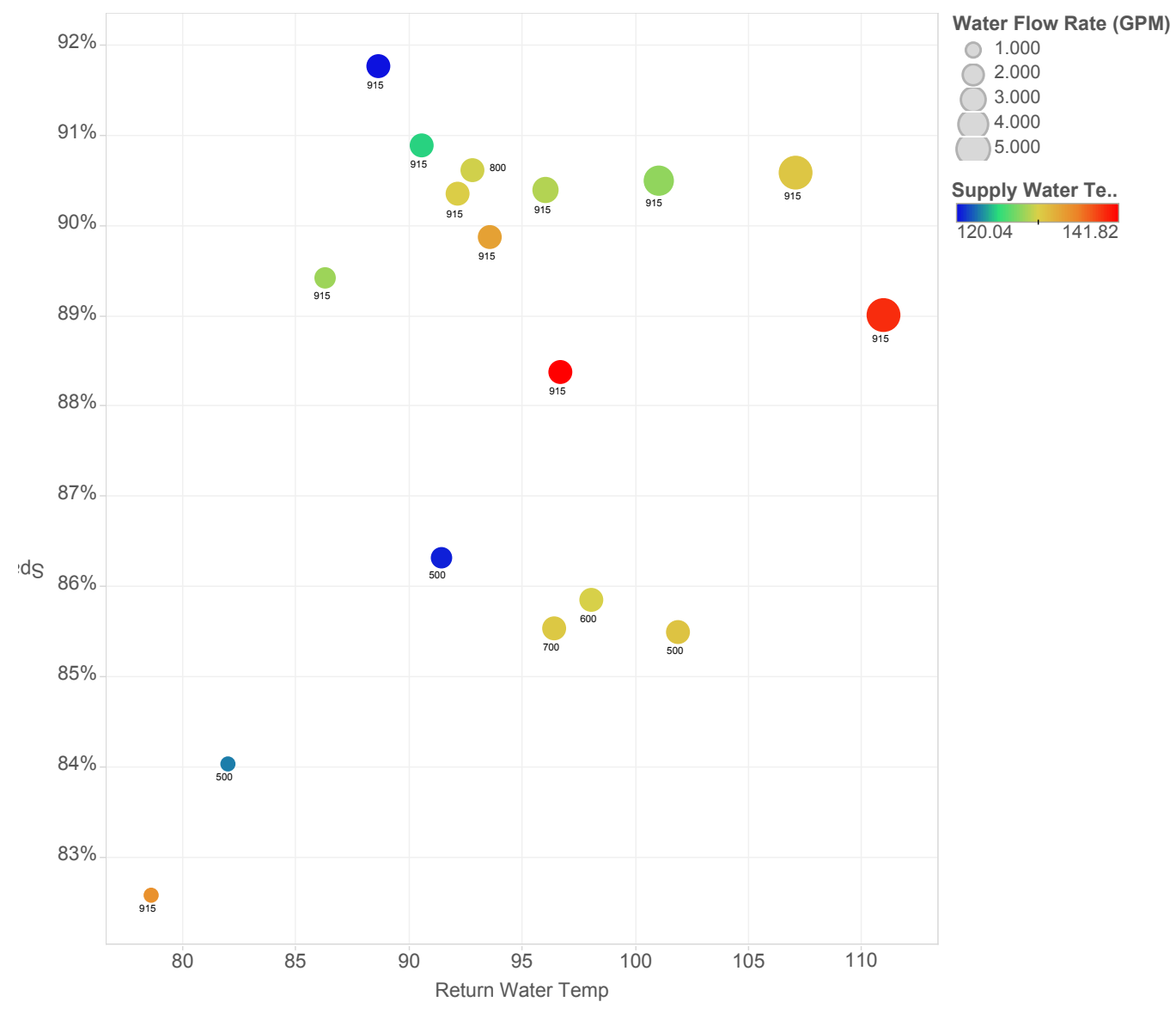

Figure 11. Steady-state space-heating test results: Navien boiler

\subsubsection{Short Cycling}

Combi systems were tested with various duty cycles in the laboratory to assess the impacts of short cycling. These tests were conducted by simulating a call for heat for a specified on cycle period, followed by an off period. The on/off cycles were repeated until a consistent efficiency was determined (with at least three on and off periods). The cycle length had a slight effect on the SWH-based system efficiency. For storage appliances with fixed burner input rates (Polaris and Vertex), the burner cycling was determined by the size of the set point temperature dead band, or the degree of stored water temperature reduction that was allowed prior to reheat. The tested units were operated at $3^{\circ}-8^{\circ} \mathrm{F}$ dead band. The dead band temperature range must balance idle losses and delivered water temperature. ND SWHs typically have dead bands higher than $20^{\circ} \mathrm{F}$. Figure 12 shows that the burner cycles were short, even for long space-heating events. The appliances maintained efficiencies within $2 \%$ of steady-state performance with these short burner cycles. The SWH with a modulating burner (Phoenix) reduced the burner capacity as the events reached completion to increase cycle length. Even during very short space-heating events, these burners ran for at least 5 minutes (Figure 13). 


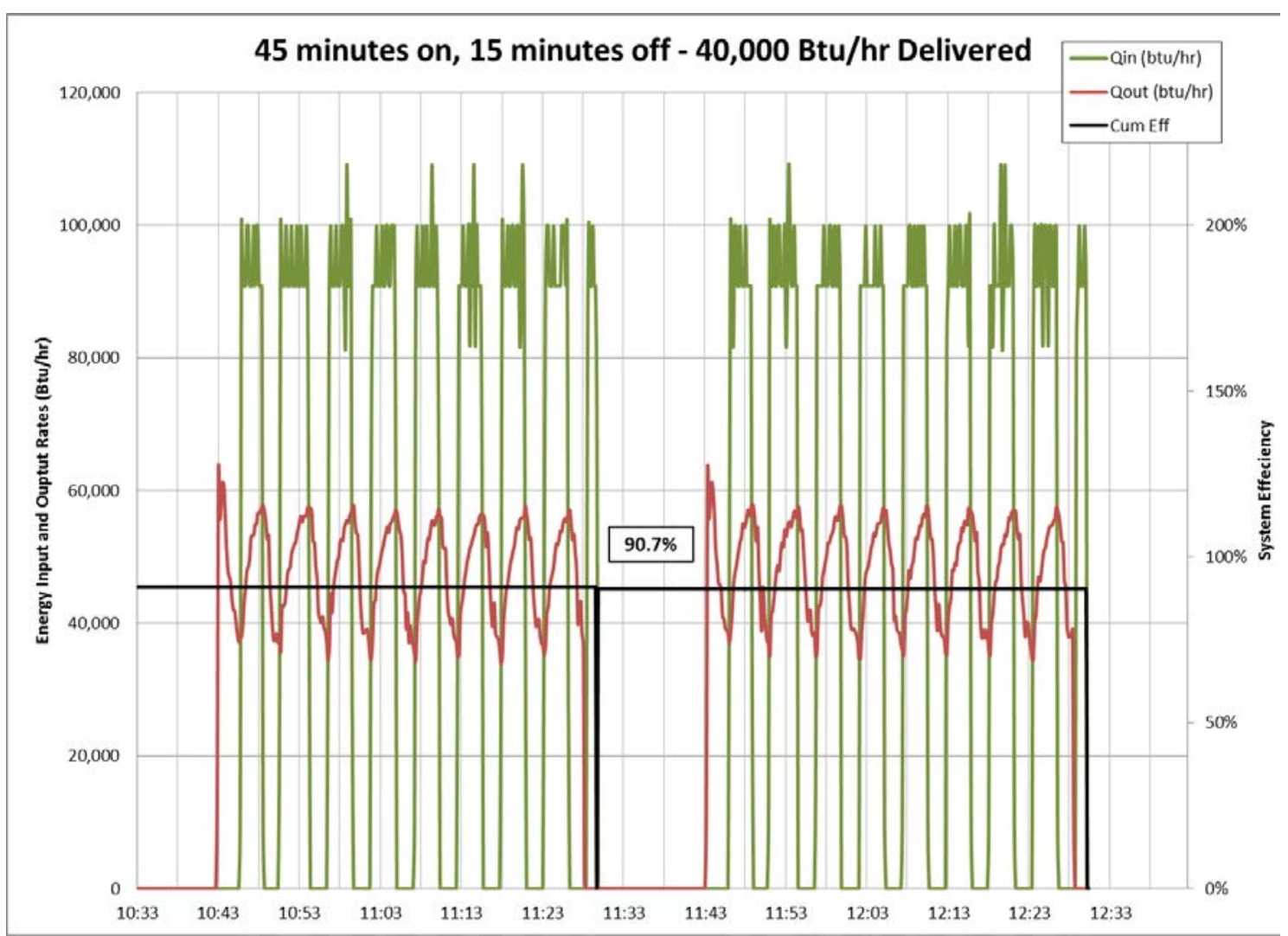

Figure 12. Cycling operation of an SWH-based fixed input combi system using a Polaris water heater

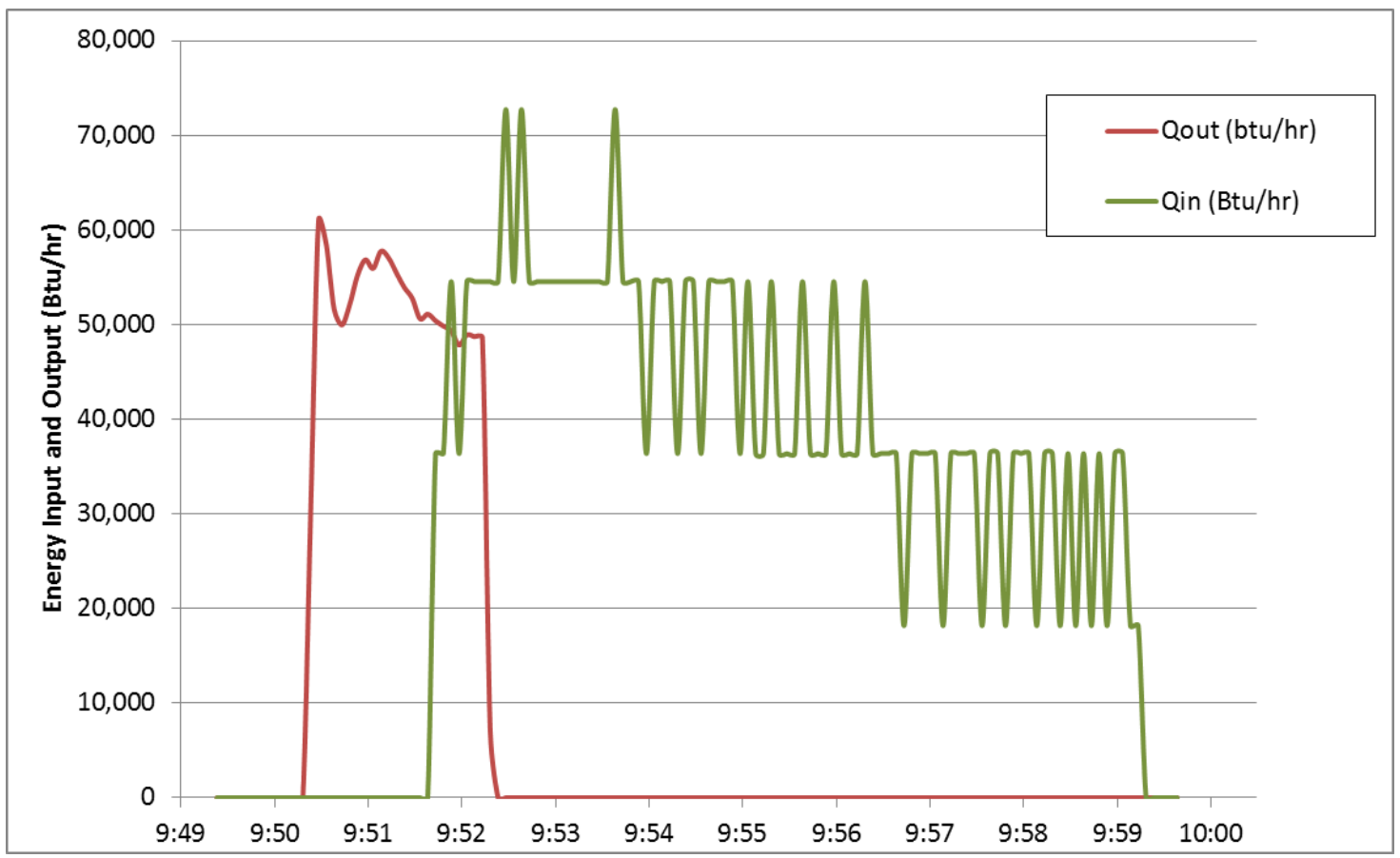

Figure 13. Cycling performance for combi systems with modulating burners (Phoenix water heater) 
The hybrid water heaters and boilers had larger reductions in efficiency with shorter spaceheating events. These products had larger startup and cooldown losses than other combi systems. If cycling for part-load conditions had been included in the modeling, these effects would likely have caused even larger reductions in efficiency with longer off periods. Systems with small or no storage capacity have cold start losses when the heat exchanger and burner have cooled to ambient conditions and must be reheated before water can be heated. These effects have been well documented for water heaters (Hoeschele and Springer 2008; Bohac et al. 2010). Figure 14 and Table 10 show the efficiencies for short space-heating events ( 2 minutes on and 10 minutes off, 5 minutes on and 10 minutes off) and steady-state operation.

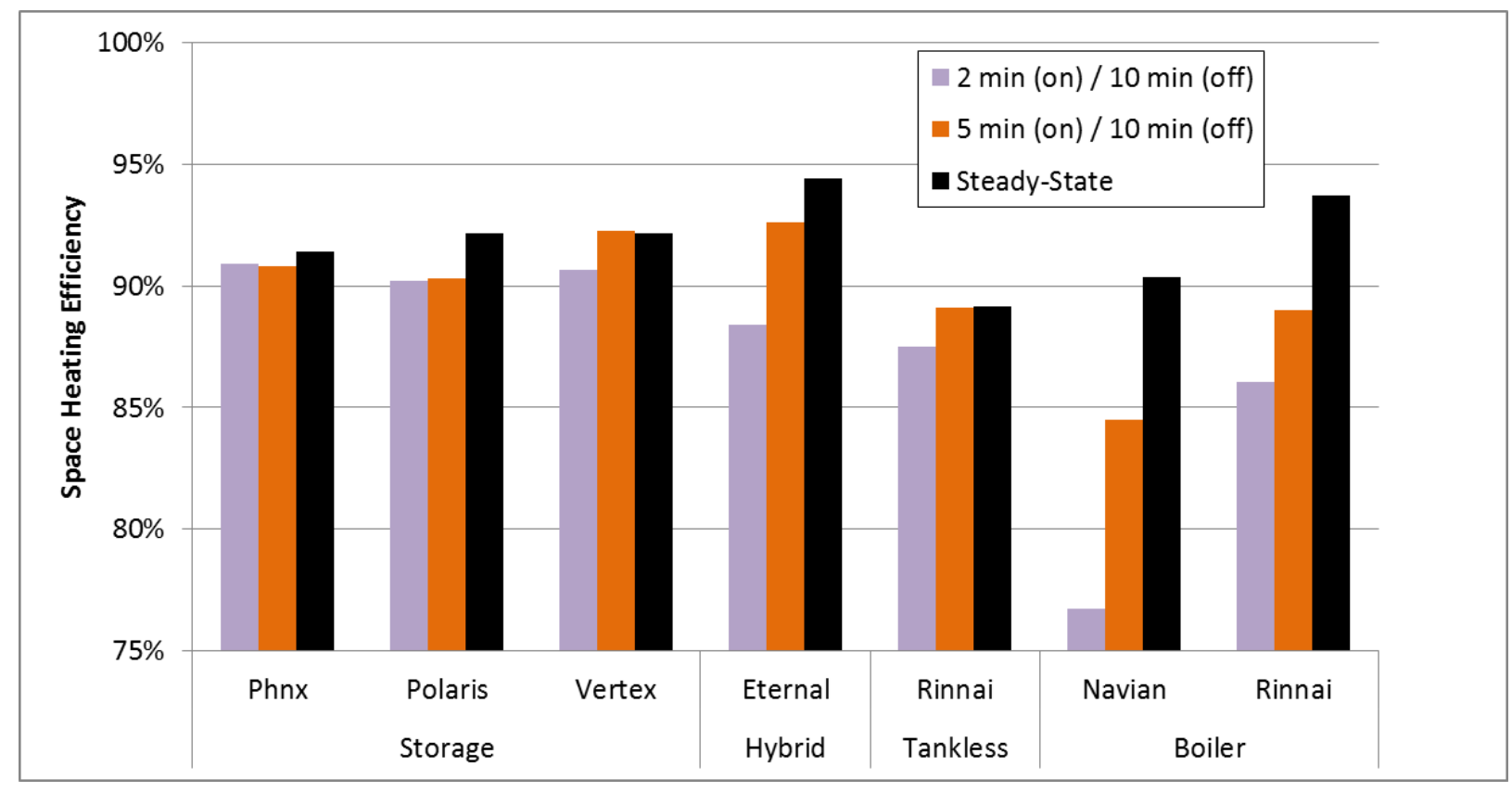

Figure 14. Impacts of short space-heating events on combi efficiency

Table 10. Impacts of Short Space-Heating Events on Combi Efficiency

\begin{tabular}{|c|c|c|c|c|c|c|c|}
\hline & \multicolumn{3}{|c|}{ Storage } & \multirow{2}{*}{$\begin{array}{c}\text { Tankless } \\
\text { Rinnai } \\
\end{array}$} & \multirow{2}{*}{$\begin{array}{l}\text { Hybrid } \\
\text { Eternal }\end{array}$} & \multicolumn{2}{|c|}{ Boiler } \\
\hline & Phoenix & Polaris & Vertex & & & Navian & Rinnai \\
\hline $\begin{array}{l}2 \min (\text { on)/ } \\
10 \min (\text { off) }\end{array}$ & $90.9 \%$ & $90.2 \%$ & $90.6 \%$ & $87.5 \%$ & $88.4 \%$ & $76.7 \%$ & $86.1 \%$ \\
\hline $\begin{array}{c}5 \mathrm{~min}(\text { on)/ } \\
10 \mathrm{~min}(\mathrm{off})\end{array}$ & $90.8 \%$ & $90.3 \%$ & $92.3 \%$ & $89.1 \%$ & $92.6 \%$ & $84.5 \%$ & $89.0 \%$ \\
\hline Steady-State & $91.4 \%$ & $92.2 \%$ & $92.2 \%$ & $89.2 \%$ & $94.4 \%$ & $90.3 \%$ & $93.7 \%$ \\
\hline Reduction S-S to $2 / 10$ & $0.6 \%$ & $2.1 \%$ & $1.7 \%$ & $1.9 \%$ & $6.4 \%$ & $15.1 \%$ & $8.1 \%$ \\
\hline
\end{tabular}

The combi system control strategies further minimized the short cycling impacts. The control strategies matched the space-heating capacity of the system to the heating load of the home. The space-heating events would be longer with control strategies than without. Therefore, the impacts of short cycling would be greater for the constant set point base case and the predicted savings would be higher for the SP reset and full modulation control methods. 


\subsubsection{Additional Benefits}

Several benefits were identified for the set point temperature and flow rate control strategies. In addition to the efficiency improvements and energy savings, both strategies can reduce the combi systems' dependence on site-specific optimization. The analysis conducted for this report assumed that the constant set point control strategy was accurately optimized for the design load of the system. To achieve this optimization in practice, the design load of the home must be accurately known and a careful optimization protocol followed. The SP reset and full modulation control methods can significantly simplify the optimization process. Installers would not need to worry about balancing the necessary design output capacity to achieve high system efficiency, because either control strategy can respond to large demands by ramping up to a higher output capacity stage.

The analysis used a high-performance AHU because it was capable of the largest water temperature drop (e.g., highest heating output), which resulted in the lowest return water temperatures. Table 11 shows that optimization would produce greater savings for a combi system with a standard AHU. AHUs with a smaller water temperature drop have higher return water temperatures and lower efficiencies. With these AHUs the benefit of reducing the output capacity in the shoulder seasons would be much greater than with the optimized, highperformance AHU. For a medium-load house with an Eternal combi system and a highperformance AHU, the set point reset temperature control strategy reduced the annual energy consumption by $3 \%$ over the constant set point control system (SP 140). Under the same circumstances with the standard AHU, the set point control would save $12 \%$ of the annual energy use.

Table 11. Eternal Water Heater Based Combi System Performance Bins for Operation at 5 GPM and 900 CFM

\begin{tabular}{c|c|c|c}
\hline $\begin{array}{c}\text { Space-Heating } \\
\text { Output } \\
(\mathbf{B t u} / \mathbf{h})\end{array}$ & $\begin{array}{c}\text { Set Point } \\
\text { Temperature } \\
\left({ }^{\circ} \mathbf{F}\right)\end{array}$ & $\begin{array}{c}\text { Return Water } \\
\text { Temperature } \\
\left({ }^{\circ} \mathbf{F}\right)\end{array}$ & $\begin{array}{c}\text { System } \\
\text { Efficiency } \\
(\%)\end{array}$ \\
\hline \multicolumn{4}{|c|}{ High-Performance AHU } \\
\hline $\mathbf{6 8 , 8 1 0}$ & 140 & 113 & $86.6 \%$ \\
$\mathbf{6 3 , 4 3 7}$ & 135 & 110 & $90.2 \%$ \\
$\mathbf{5 9 . 6 2 5}$ & 130 & 106 & $91.8 \%$ \\
\hline $\mathbf{5 5 , 0 3 2}$ & 125 & 103 & $92.3 \%$ \\
\hline $\mathbf{5 0 , 4 3 9}$ & 120 & 100 & $92.8 \%$ \\
\hline \multicolumn{4}{|c|}{ Standard $\mathbf{A H U}$} \\
\hline $\mathbf{4 3 , 4 6 4}$ & 140 & 123 & $75.3 \%$ \\
\hline $\mathbf{4 0 , 7 1 2}$ & 135 & 119 & $79.7 \%$ \\
$\mathbf{3 7 , 9 6 1}$ & 130 & 115 & $84.2 \%$ \\
$\mathbf{3 5 , 1 0 2}$ & 125 & 111 & $88.6 \%$ \\
$\mathbf{3 2 , 2 4 2}$ & 120 & 107 & $91.6 \%$ \\
\hline
\end{tabular}


These results also show the value of using the high-performance over the standard AHU for all control methods. For example, for a medium-load house with a combi system using an Eternal hybrid water heater and constant set point control (SP 140) the high-performance AHU saves $9 \%$ (90.4 therms/year) compared to the standard AHU. The added equipment cost is about $\$ 650$.

\subsection{Field Tests}

\subsubsection{Set Point Reduction}

Five of the 20 field test sites from the previous study were available for continued monitoring. Sites were selected if homeowners were willing to allow monitoring to continue and the design space-heating load could be provided with a reduced set point temperature. The five sites included systems with three different heating plants (Table 12). The set point temperatures were adjusted from $140^{\circ} \mathrm{F}$ to $130^{\circ} \mathrm{F}$ for four of the sites; the fifth site $(1031)$ was reduced to $135^{\circ} \mathrm{F}$. Further reduction of the set point temperature at site 1031 would have reduced the capacity of the combi system below the design load plus a $20 \%$ safety factor.

Table 12. Field Monitoring Sites and Combi System Equipment

\begin{tabular}{c|c|c|c|c|c}
\hline \multirow{2}{*}{ Site } & \multirow{2}{*}{$\begin{array}{c}\text { Heating } \\
\text { Plant }\end{array}$} & $\begin{array}{c}\text { Type of Heating } \\
\text { Plant }\end{array}$ & \multirow{2}{*}{ AHU } & \multicolumn{2}{|c}{$\begin{array}{r}\text { Set Point Temperature } \\
\left({ }^{\circ} \mathbf{F}\right)\end{array}$} \\
\cline { 5 - 6 } & & & Pre & Post \\
\hline $\mathbf{1 0 2 7}$ & Polaris & SWH & Ennerzone & 140 & 130 \\
$\mathbf{1 0 3 1}$ & Polaris & SWH & Ennerzone & 140 & 135 \\
$\mathbf{1 0 5 6}$ & Phoenix & SWH & Ennerzone & 140 & 130 \\
$\mathbf{1 0 4 9}$ & Eternal & SWH & Ennerzone & 140 & 130 \\
$\mathbf{1 0 7 0}$ & Eternal & SWH & Ennerzone & 140 & 130 \\
\hline
\end{tabular}

Average annual efficiency and annual energy consumption were computed for the combi systems with reduced set point temperatures. The analysis was completed using the linear input/output method used for the previous project (Schoenbauer et al. 2014).

Table 13 shows the results from the field analysis. The set point reductions resulted in a $1 \%-4 \%$ increase in annual energy savings. Because of the small sample size and the differences in the combi system equipment and operation at each site, a detailed analysis of savings with other parameters was not possible. However, these results show general agreement with the laboratory estimates of increased efficiency with decreased return water temperature. These combi systems had been previously optimized as part of the initial installation. The set point temperature was reduced, but the water flow and airflow rates were not changed. The set point reductions at these five sites resulted in an average reduction in return water temperature of $4^{\circ} \mathrm{F}$. The laboratory tests indicate that a $10^{\circ} \mathrm{F}$ set point reduction will result in improvements in steady-state efficiency from 1.2 to 1.6 percentage points for the three SWHs included in this field test (Table 14). 
Table 13. Efficiency and Energy Use Improvements from Set Point Reduction

\begin{tabular}{|c|c|c|c|c|c|c|c|c|c|}
\hline \multirow[t]{2}{*}{ Site } & \multirow{2}{*}{$\begin{array}{c}\text { Heating } \\
\text { Plant }\end{array}$} & \multirow{2}{*}{$\begin{array}{l}\text { Set Point } \\
\text { Reduction } \\
\left({ }^{\circ} \mathbf{F}\right)\end{array}$} & \multicolumn{3}{|c|}{$\begin{array}{c}\text { Annual Efficiency } \\
(\%)\end{array}$} & \multicolumn{4}{|c|}{$\begin{array}{c}\text { Annual Energy Use } \\
\text { (therms) }\end{array}$} \\
\hline & & & Pre & Post & Change & Pre & Post & & $\operatorname{lgs}$ \\
\hline 1027 & Polaris & 10 & 85.3 & 89.0 & 3.6 & 809 & 776 & 33 & $4.1 \%$ \\
\hline 1031 & Polaris & 5 & 84.5 & 86.9 & 2.4 & 773 & 751 & 22 & $2.8 \%$ \\
\hline 1056 & Phoenix & 10 & 84.0 & 86.1 & 2.1 & 551 & 538 & 14 & $2.5 \%$ \\
\hline 1049 & Eternal & 10 & 89.9 & 91.0 & 1.1 & 668 & 661 & 8 & $1.2 \%$ \\
\hline 1070 & Eternal & 10 & 88.8 & 90.5 & 1.7 & 507 & 498 & 10 & $1.9 \%$ \\
\hline
\end{tabular}

Table 14. Steady-State Space Heating Laboratory Results for SWHs (2.5 GPM and 900 CFM)

\begin{tabular}{c|c|c|c|c}
\hline Test ID & $\begin{array}{c}\text { Set Point } \\
\text { Temperature } \\
\left({ }^{\circ} \mathbf{F}\right)\end{array}$ & Polaris & Phoenix & Eternal \\
\hline Test $\mathbf{1}$ & 140 & $90.6 \%$ & $90.1 \%$ & $93.2 \%$ \\
\hline Test 2 & 135 & $92.2 \%$ & $91.2 \%$ & $93.8 \%$ \\
Test 3 & 130 & $92.2 \%$ & $91.4 \%$ & $94.4 \%$ \\
\hline
\end{tabular}

\subsubsection{Domestic Hot Water Priority}

Field data from the previous study were used to evaluate the potential of DHW priority to improve space-heat delivery and reduce the required peak capacity of the combi system. The first area of evaluation for DHW priority was the impact on the conditioned air temperature. This control strategy prevents space heating during DHW draws. In a home with high continuous hot water use, this may prevent the space heating from running for long periods. The conditioned air temperature data in each home with DHW priority were analyzed. The biggest area of concern was homes with multiple morning showers back to back, simultaneous with recovery from a nighttime temperature setback. Site 1037 had DHW priority, an average daily hot water use of 75 gal, and a $6^{\circ} \mathrm{F}$ heating nighttime setback. The average conditioned space temperature was compared for peak heating season days with low DHW use (less than 30 gal) and high DHW use (more than 90 gal). Figure 15 shows that when DHW use was low, the space heating system recovered from the nighttime setback in about 2 hours (from 5 a.m. to 7 a.m.). When DHW use was high and the combi system prioritized DHW over space heating, recovery from setback took 4-7 hours and did not reach peak temperatures until noon. The system was able to recover about $75 \%$ of the setback prior to 8:00 a.m. However, the recovery rate appears to be significantly higher for the low DHW days than for the high DHW days. This recovery problem was found only in homes with nighttime setback and large (more than 90 GPD) DHW loads. The other four sites with DHW priority did not experience this effect, because they had smaller DHW loads and/or no nighttime setback. 


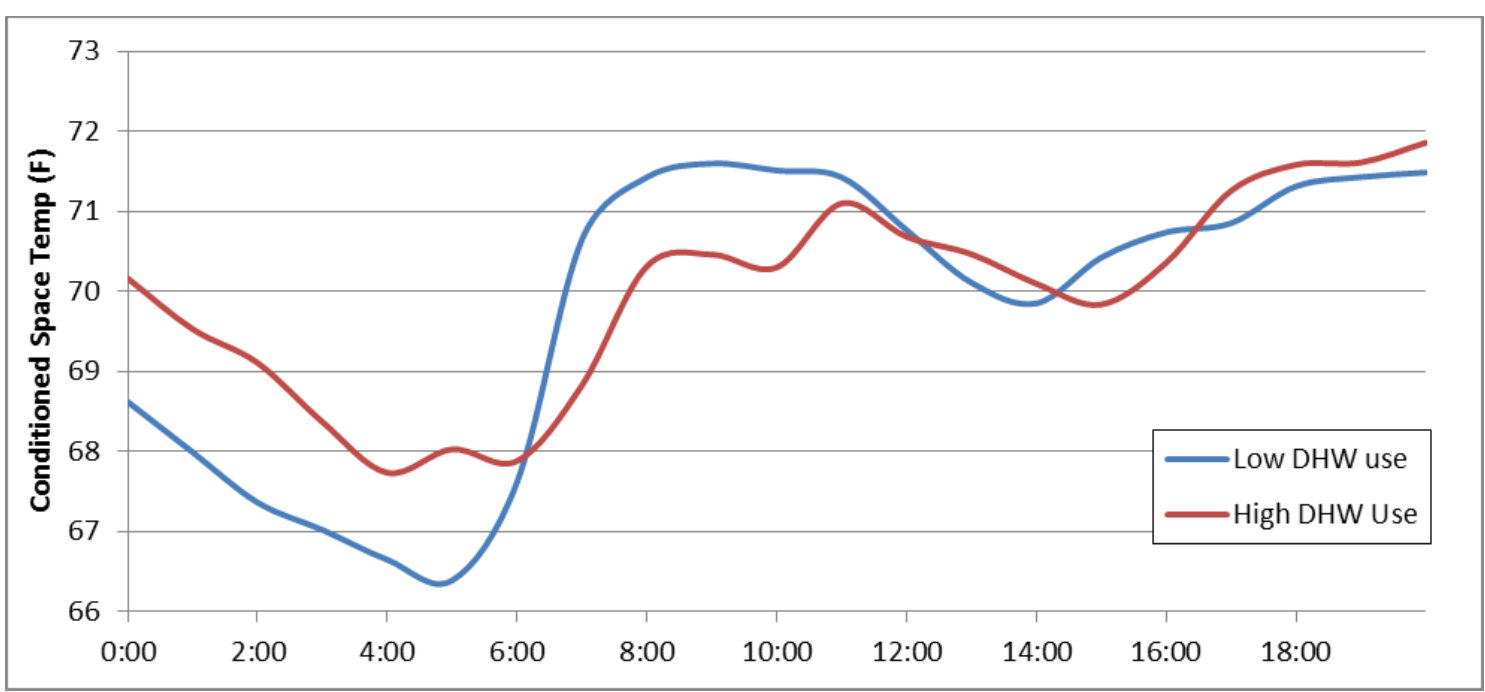

Figure 15. Conditioned space temperature during peak heating season for days with high and low DHW use (Site 1037)

The second potential impact of DHW priority is the variation in supply water temperature under simultaneous DHW and space-heating draws. Certain DHW draws, such as showers, require hot water at a specific, constant temperature. Without DHW priority, a call for space heat during this type of DHW draw has the potential to change the temperature of the hot water. Field data from past monitoring data were analyzed to determine the impact of space-heating events on DHW delivered water temperature.

A TWH-based combi system was most susceptible to simultaneous use impacts. With no storage capacity, the TWH relied on the modulation of the burner output to respond to the change in loads when a second draw was initiated or completed. Figure 16 shows a large DHW draw (3 GPM) with a space-heating draw that starts during the water draw at time equals 0 seconds. TWHs restrict the water flow rate as necessary to ensure the outlet temperature requirement is met. For the combi systems installed in the field monitoring project, the water heaters were set to $140^{\circ} \mathrm{F}$ (the blue line in Figure 16) and a mixing valve was used to temper the outlet water for DHW use (the black line in Figure 16). For this large DHW draw the flow restriction of the TWH prevented a great impact from the space-heating system (initially the space-heating water flow rate was restricted below $0.5 \mathrm{GPM}$ ).

The start of the space-heating draw triggered very slight instability in the tempered water temperature (less than $\left.0.5^{\circ} \mathrm{F}\right)$. Figure 17 shows a smaller DHW draw (0.8 GPM) on the same system. Because the DHW flow rate was lower, the space heating water flow rate was not restricted and it had a greater impact on the water temperature. In this case a $5^{\circ} \mathrm{F}$ temperature decrease in the tempered DHW temperature was measured at the start of the space-heating draw and an $8^{\circ} \mathrm{F}$ increase was measured at the end. These are significant fluctuations in water temperature, and in these instances a very low-flow shower head located close to the combi system may cause discomfort. Long pipe runs between the water heater and the end use will help reduce some of the short-term fluctuations. 

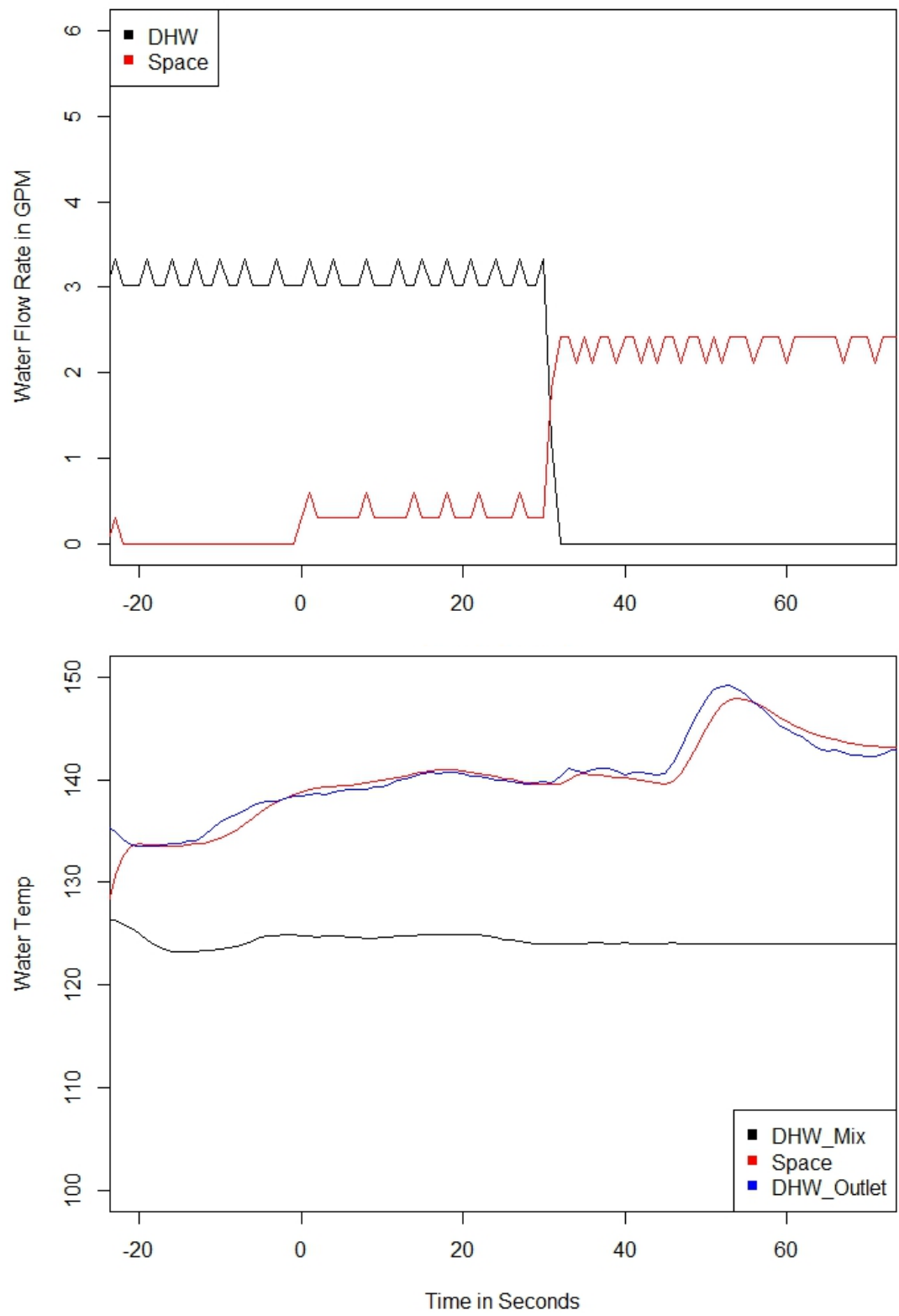

Figure 16. Simultaneous DHW and space-heating draws with a TWH-based combi system 

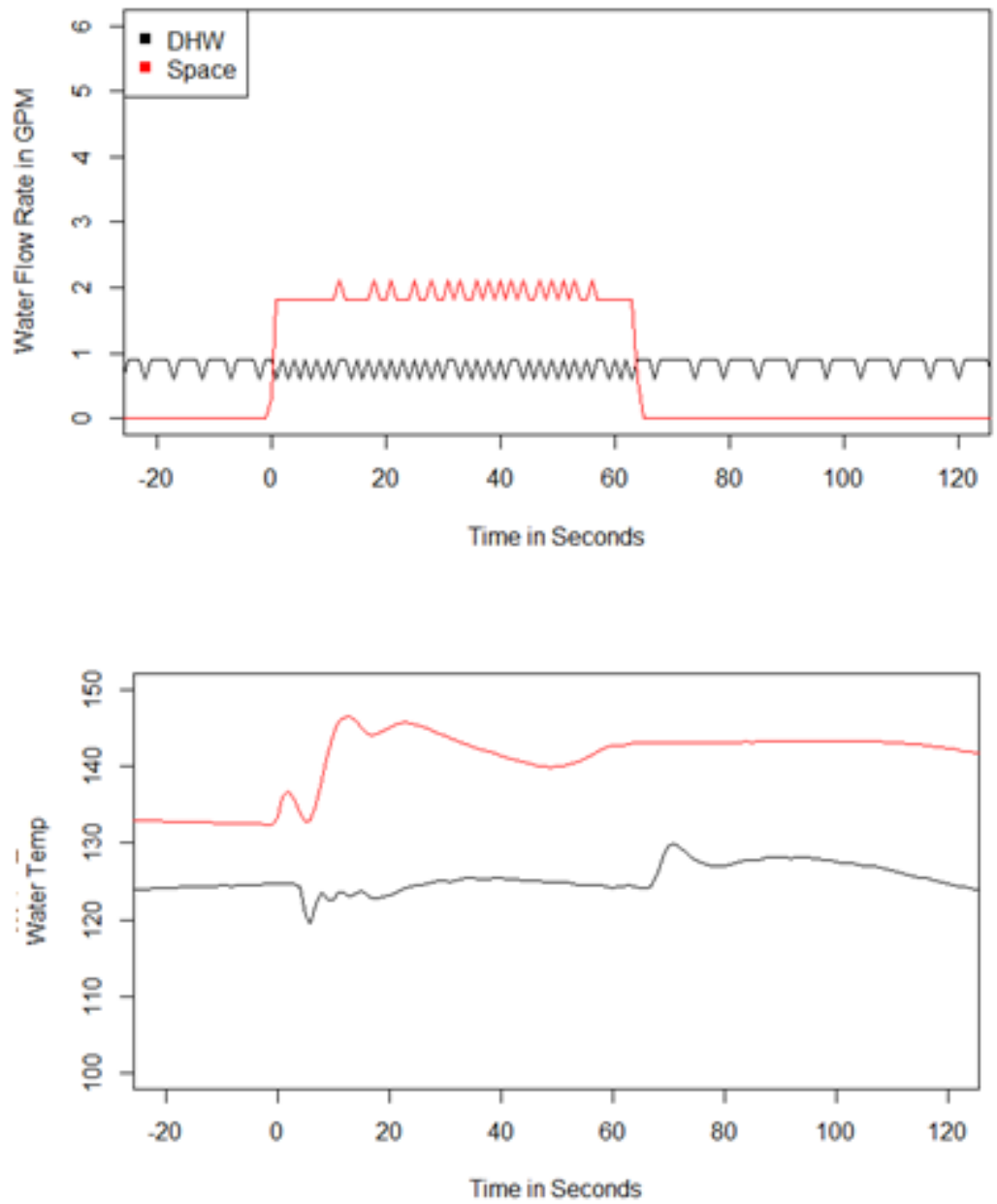

Figure 17. A small DHW draw interrupted by a space-heating draw with a TWH-based combi system

The SWH-based systems had no DHW priority or flow restriction controls in place. When DHW and space heating draws happened simultaneously, the system provided hot water to both end uses at the same rates as during independent uses. Figure 18 shows a simultaneous use event. The DHW outlet water temperature (blue) and space heating water temperature (red) rise and fall (about $0.5^{\circ} \mathrm{F}$ per minute) as the storage tank burner cycles on and off to keep the storage water temperature at set point. The tempering value reduces the mixed temperature fluctuation even further. This event had no increased water temperature variance caused by the combi system in the SWH-based system. 

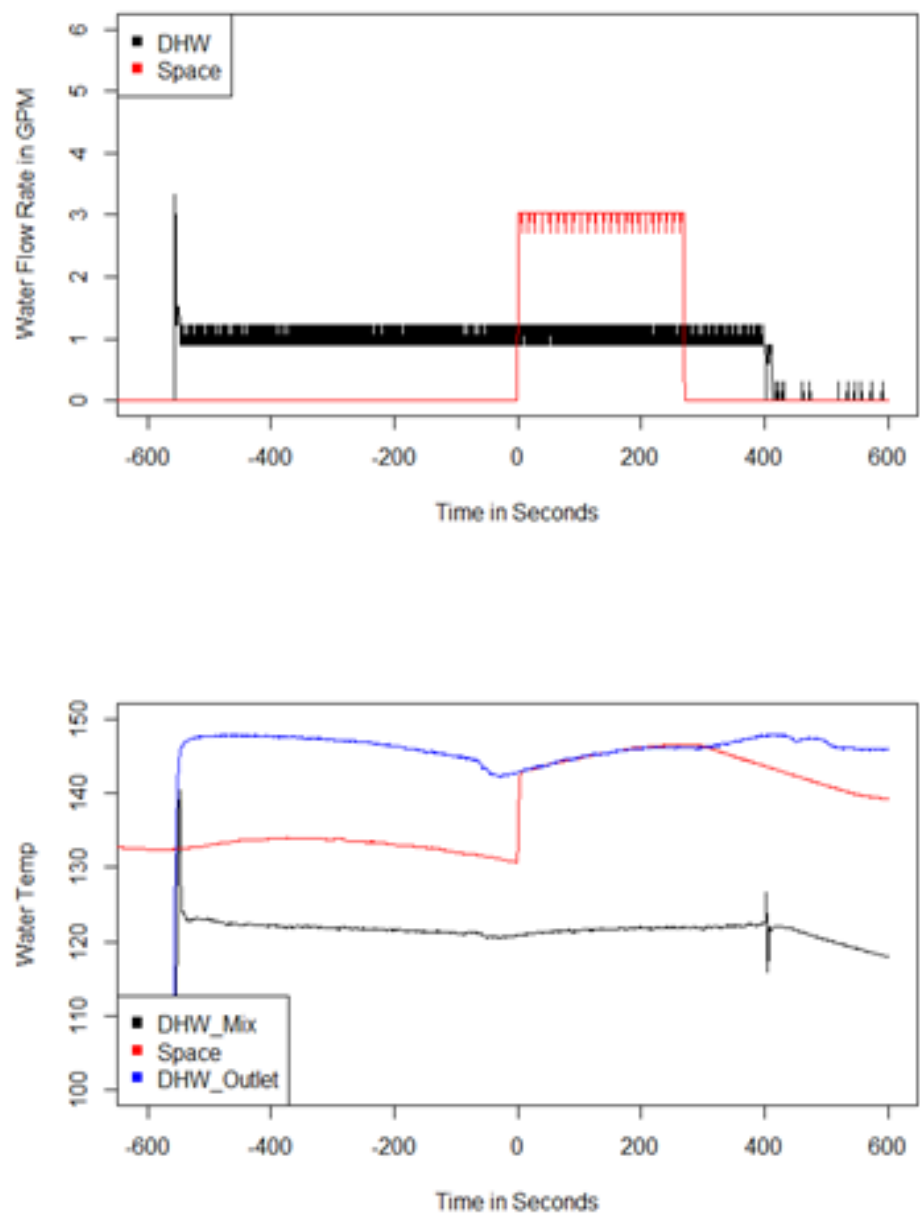

Figure 18. Simultaneous DHW and space heating draws on a SWH-based combi system

Five boilers were installed and monitored in the previous field monitoring project. Each used DHW priority. During the full heating season no simultaneous space heating and DHW draws occurred at any of these five sites. Occasionally a space-heating draw and a DHW draw would begin at about the same time, but the space-heating draw would give priority to the DHW draw and shut down within 3 seconds. Figure 19 shows a 30-second DHW draw that occurred during the space-heating draw. When the draw was initiated, the boiler stopped the space-heating water flow and switched to its DHW supply mode. It provided hot water for DHW at $120^{\circ} \mathrm{F}$ until the DHW draw was completed, at which time it returned to space-heating operation. 

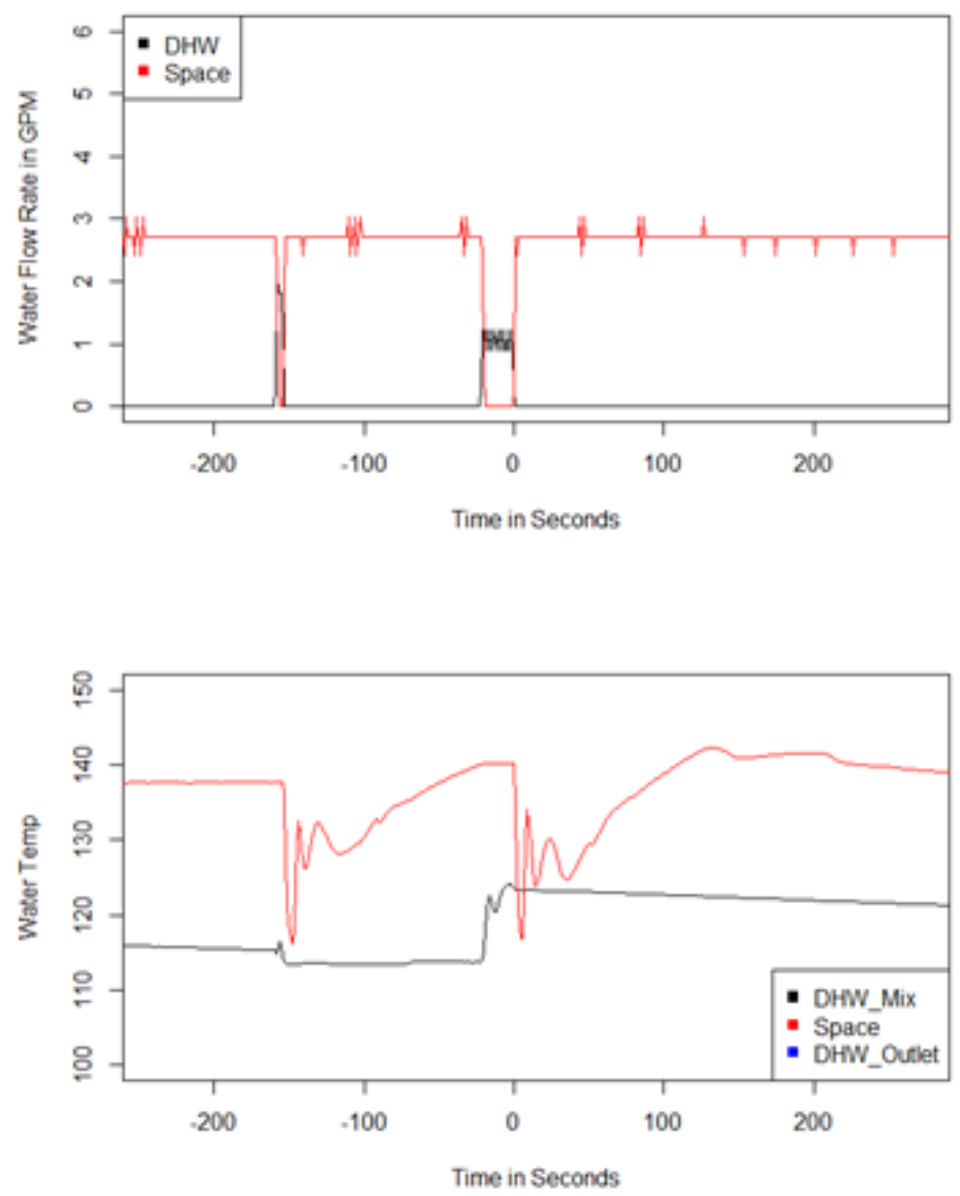

Figure 19. DHW priority operation on a combi boiler system 


\section{Conclusions}

Better insulation and tighter envelopes reduce space-heating loads for new and existing homes. These reduced loads enable a combined space- and water-heating system to meet the combined loads. Combi systems have been used on a limited basis for many years but have only recently been used as a high-efficiency option. First-generation high-efficiency systems reduce annual space- and water-heating gas consumption by $19 \%$ but require site-specific design and optimization. These systems use a single space-heating stage with a fixed output capacity. This project has shown that controls can significantly benefit these systems. Two control methods were analyzed:

- Set point temperature reset control, which reduced the supply water temperature for periods of lower space-heating demand. This measure can be implemented with an outdoor air temperature reset control, which is commonly done for high-performance boilers.

- Flow rate modulation, which controlled the set point temperature and varied the water flow and airflow rates through the AHU.

Both strategies were used to reduce the output capacity of the space-heating system as the load was reduced on the home.

Laboratory tests and daily load/performance models showed that the set point temperature reset control produced a savings of 2.1\%-4.3\% (20-40 therms/year) for SWH and hybrid water heater combi systems operated in medium-load homes. The full modulation control showed additional savings over set point control (in high-load homes, which almost doubled the savings: 4\%-5\% over the no-control case). The reset control can be implemented for $\$ 200-\$ 400$, which would provide paybacks of 6-25 years for low-load houses and 3-15 years for high-load houses. Offthe-shelf equipment is not currently available for full modulation, but high-performance AHU components could be used for full modulation with a controller that is similar in design to an outdoor reset. These components can also help control fan and pump speed. Implementation costs would be similar to the outdoor reset and would provide paybacks of 5-1/2-20 years for lowload houses and $2-1 / 2-10$ years for high-load houses. The components required for these controllers are inexpensive and the implementation costs would be minimal when control is implemented with a new combi system installation.

The laboratory tests and analysis were conducted with a high-performance hydronic AHU with a higher heating output that produced greater water temperature drops across the AHU. The reset and fully modulating controls would produce greater savings for a combi system with a standard AHU. AHUs with a smaller water temperature drop have higher return water temperatures and lower efficiencies. With these AHUs the benefit of reducing the output capacity in the shoulder seasons would be much greater than with the optimized high-performance AHUs. For a mediumload house with an Eternal combi system and a high-performance AHU, the set point temperature control strategy reduced the annual energy consumption by $3 \%$ compared to the constant set point control system (SP 140). Under the same circumstances with the standard AHU, the set point control would save $12 \%$ of the annual energy use. The analysis also shows that a high-performance AHU is necessary for producing high system efficiencies. 
Field monitoring of five homes was conducted to measure the energy savings impact of set point reduction. The field testing and analysis showed that a reduction in set point temperature from $140^{\circ}-130^{\circ} \mathrm{F}$ resulted in an average reduction in return water temperature of $4^{\circ} \mathrm{F}$. These homes saved $1 \%-4 \%$ on their annual energy bills with the reduced set point.

Although the control strategies provided energy cost savings, the biggest benefit may be a simpler commissioning process that more reliably results in high-efficiency operation. For instance, previous NorthernSTAR research has shown that improper commissioning or inaccurate characterization of the design heating load can significantly reduce combi system efficiency. These control strategies would allow the system to automatically reduce capacity to the most efficient operating point and still meet the load. For example, the study showed that design loads were typically overestimated and had additional safety factors applied. This approach resulted in combi systems being optimized for design loads much higher than the actual design load; therefore, the return water temperature increased and the efficiency decreased. If the same systems were installed with a set point reset or fully modulating control, the system would operate at a lower capacity stage; reduced water temperature would decrease and efficiency would increase. The control system would thus reduce the design calculations and time that would be required to properly install and commission a combi system. 


\section{References}

Arena, L.B. 2010. In-Field Performance of Condensing Boilers in Cold Climate Region. Final Report. Building America. Norwalk, CT: Prepared by Steven Winter Associates, Inc. of the Consortium for Advanced Residential Buildings Team, for Building America

Bohac, D. 1992. “Once Heated, Twice Used.” Home Energy Magazine Online, July. http://www.homeenergy.org/archive/hem.dis.anl.gov/eehem/92/920708.html.

Bohac, D., M. Hewett, T. Dunsworth, M. Hancock, and T. Staller. 1991. Retrofit Savings for Dual Integrated Appliances in Small Commercial and Multifamily Buildings. Report to Minnegasco Inc. Center for Energy and the Urban Environment. www.mncee.org/pdf/tech pubs/90-5.pdf.

Butcher, T. 2006. "Condensing Boilers and Baseboard Hydronic Distribution Systems." ASHRAE Transactions 112 (1).

Butcher, T. 2011. The DHW Performance of Heating Boilers presented at the ACEEE Water heating Forum, May 10, Berkeley, CA. http:/www.aceee.org/files/pdf/conferences/hwf/2011/7A\%20$\% 20$ Tom\%20Butcher.pdf.

Hoeschele, M., and D. Springer. 2008. "Field and Laboratory Testing of Gas Tankless Water Heater Performance." ASHRAE Transactions 114 (Part 2).

Schoenbauer, B., M. Hewett, and D. Bohac. 2010. Actual Savings and Performance of Natural Gas Tankless Water Heaters. Minneapolis, MN: Center for Energy and Environment, October 18. www.mncee.org/research/tankless_water heaters/index.php.

Schoenbauer, B., D. Bohac, P. Huelman, M. Hewett, and J. McAlpine. 2012. "Retrofitting Combined Space and Water Heating Systems: Laboratory Tests.” Washington, D.C.: U.S. Department of Energy. http://www.mncee.org/getattachment/623786cd-c32f-4ba7-80fcb229f1fa8a37/.

Schoenbauer, B., D. Bohac, P. Huelman, and J. McAlpine. 2014. "Retrofitting Combined Space and Water Heating Systems: Field Assessment." Washington, D.C.: U.S. Department of Energy.

Thomas, M. 2011. “Combination Systems Good or Bad?” Presented at the ACEEE Water Heating Forum 2011, May 10, Berkeley, CA. www.acee.org/files/pdf/conferences/hwf/2011/7A\%20-\%20Martin\%20Thomas.pdf. 


\section{Appendix: Solution Center Content}

\section{Guide Title: Combined Space and Water Heating: Next Steps to Improved Performance}

Keywords: HVAC, Space heating, water heating, condensing, low-load homes

Climate Zone: Heating climates, zones 4-8

Construction Type: New construction and/or existing homes.

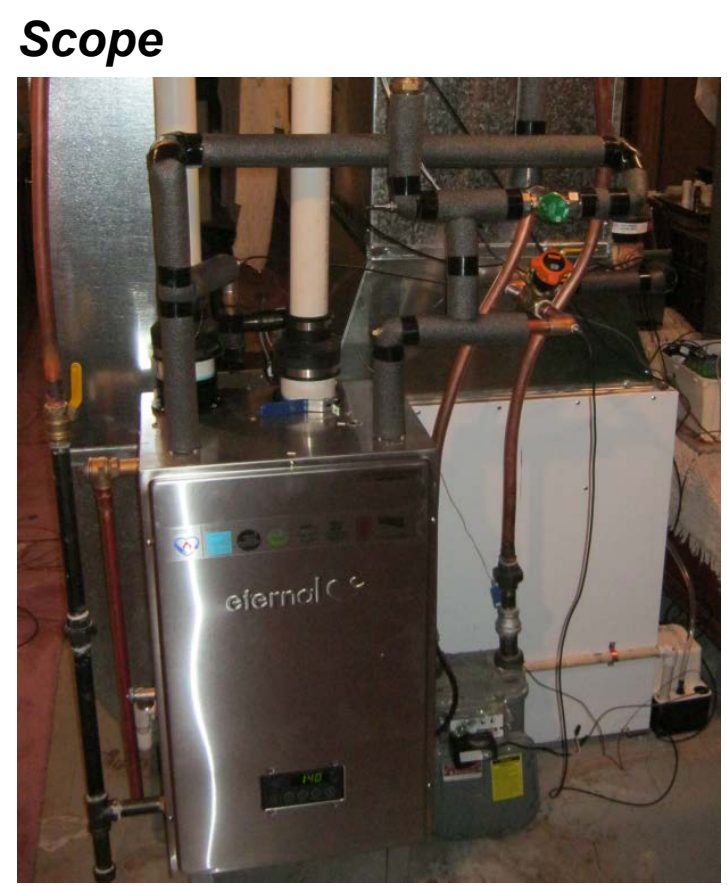

Image Title: Combi system installed in a retrofit home providing both space and water heating Image Source: Schoenbauer. 2012. Center for Energy and Environment. Unpublished.

Display Image Filename: Combi_Hybrid_001.jpeg

Efficient HVAC Equipment

ENERGY STAR Version 3 (Rev. 06)

\section{Description}

New housing construction practices and present-day retrofit measures are leading to more thermally efficient building envelopes and the decline of home space heating loads. At the same time, new water heating product lines with higher firing rates are becoming the dominant thermal engines in an increasing number of homes. Instead of continuing to specify two separate thermal engines - such as a separate gas-fired furnace and water heater-researchers, homebuilders, and HVAC/DHW equipment manufacturers are exploring more cost-effective packaging of space and water heating in a new generation of combination systems that use high-efficiency condensing heating plants and high-performance hydronic air coils to provide both space and water heating.

Condensing combi systems are still relatively new and complex, often requiring onsite engineering and optimization to achieve desired performance. Improved controls have the 
potential to reduce some of this installation and operational complexity and improve upon the measured performance. The control measures evaluated in the laboratory include temperature set point control (outdoor reset and/or turndown after heating season), space heating modulation (both water flow and airflow) and DHW priority. The benefits to installation, sizing, and optimization were characterized for all three control schemes. Set point control and space heating modulation were analyzed for efficiency and energy savings improvements through laboratory and field testing.

\section{Ensuring Success}

High-efficiency combination systems are an emerging technology and many installers were unfamiliar with their installation and optimization. Verification of proper installation was necessary to achieve the desired results of a safe, comfortable, and efficient space and water heating system. After training contractors, installing systems, and verifying installations, the following process was developed to verify future installations.

1. Combi system installed using approved high-performance equipment

2. Installer must have received an approved combi installation training

3. Field-verified performance of return water temperature or system efficiency during operation

\section{Climate}

Combi systems may be appropriate for all climate zones. However, control and optimization specifics will vary. The systems discussed here are optimized for heating-dominated climates.

\section{Training}

\section{Presentations}

1. Presentation Title: Performance and Optimization of Residential Condensing Combi Systems Presentation Source: http://mncee.org/Innovation-Exchange/ResourceCenter/Webinars/Performance-and-Optimization-of-Residential-Conden/

Filename: 2013_04_23 IX Webinar-Combis.pptx

\section{Compliance}

\section{More Info}

\section{Case Studies}

1. NorthernSTAR. 2014. Combined Space and Water Heating: Next Steps to Improved Performance, Minneapolis, MN. Prepared by the Center for Energy and Environment for the U.S. Department of Energy Building America Program. Upcoming

Climate Zone: Zones 4-8.

Case Study Type: Measure-specific

Construction Type: New and existing. 
2. NorthernSTAR. 2014. Retrofitting Combined Space and Water Heating Systems: Laboratory Tests, Minneapolis, MN. Prepared by the Center for Energy and Environment for the U.S. Department of Energy Building America Program. Upcoming

Climate Zone: Zones 4-8.

Case Study Type: Measure-specific

Construction Type: New and existing. 


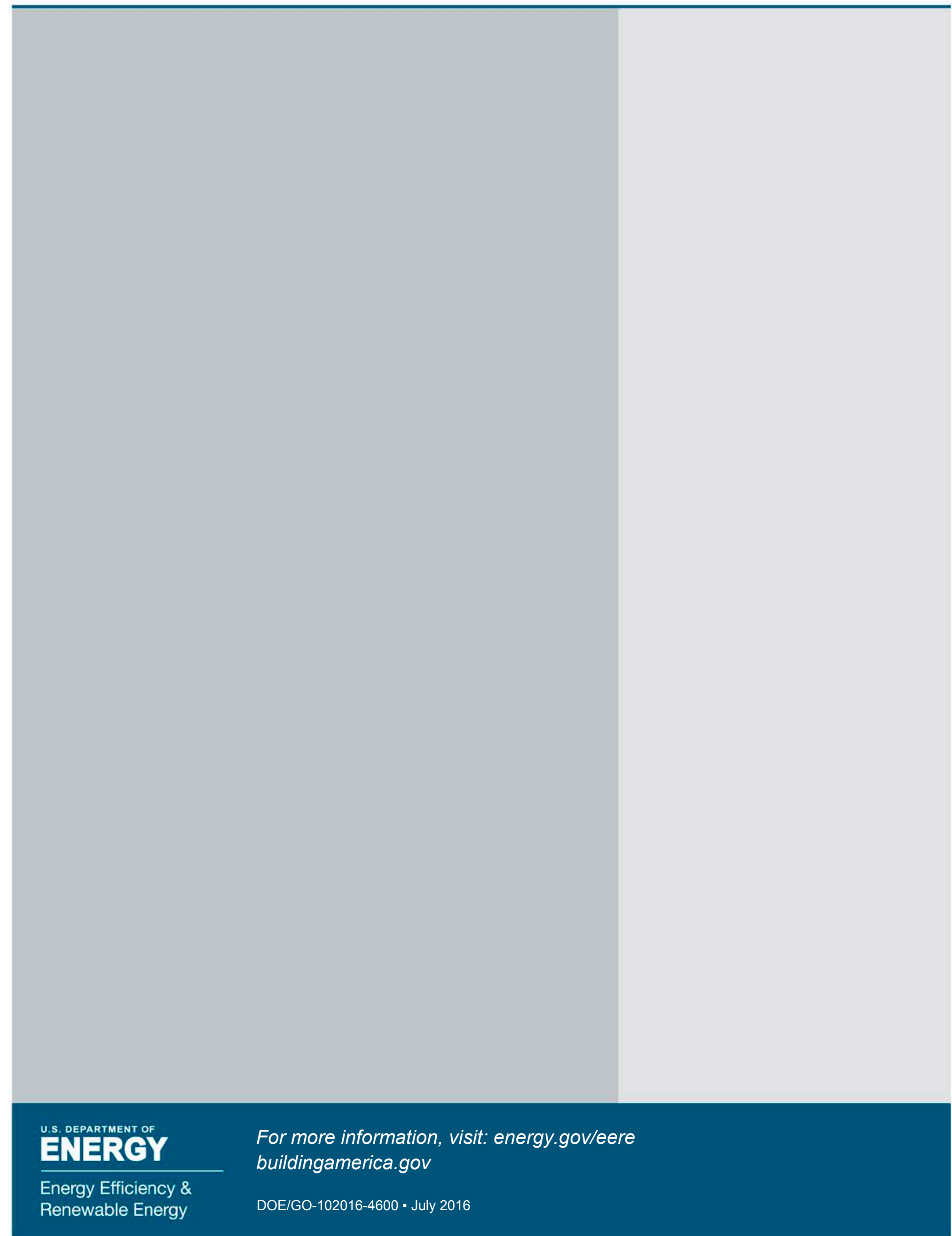

